\title{
Global gene expression profile progression in Gaucher disease mouse models
}

\author{
You-Hai Xu', Li Jia', Brian Quinn', Matthew Zamzow ${ }^{1}$, Keith Stringer², Bruce Aronow ${ }^{3}$, Ying Sun', Wujuan Zhang ${ }^{2}$, \\ Kenneth DR Setchell2, Gregory A Grabowski ${ }^{*}$
}

\begin{abstract}
Background: Gaucher disease is caused by defective glucocerebrosidase activity and the consequent accumulation of glucosylceramide. The pathogenic pathways resulting from lipid laden macrophages (Gaucher cells) in visceral organs and their abnormal functions are obscure.

Results: To elucidate this pathogenic pathway, developmental global gene expression analyses were conducted in distinct Gba1 point-mutated mice (V394L/N394L and D409 V/null). About 0.9 to 3\% of genes had altered expression patterns ( $\geq \pm 1.8$ fold change), representing several categories, but particularly macrophage activation and immune response genes. Time course analyses (12 to $28 \mathrm{wk}$ ) of INF $\gamma$-regulated pro-inflammatory (13) and IL-4-regulated anti-inflammatory (11) cytokine/mediator networks showed tissue differential profiles in the lung and liver of the Gba1 mutant mice, implying that the lipid-storage macrophages were not functionally inert. The time course alterations of the INF $\gamma$ and IL-4 pathways were similar, but varied in degree in these tissues and with the Gbal mutation.

Conclusions: Biochemical and pathological analyses demonstrated direct relationships between the degree of tissue glucosylceramides and the gene expression profile alterations. These analyses implicate IFN $\gamma$-regulated proinflammatory and IL-4-regulated anti-inflammatory networks in differential disease progression with implications for understanding the Gaucher disease course and pathophysiology.
\end{abstract}

\section{Background}

Gaucher disease, an autosomal recessive disorder, is a common lysosomal storage disease. Insufficient activity of acid $\beta$-glucosidase (glucocerebrosidase, GCase, E. C.3.2.1.45) in all cells leads to the substrate accumulation including glucosylceramide and glucosylsphingosine, and the various clinical phenotypes. The pathologic hallmark of Gaucher disease is the presence of lipid laden macrophages, a.k.a., Gaucher cells, in visceral organs [1]. The macrophages are thought to be the primary visceral cells involved in all variants, and these cells become progressively numerous and engorged with glucosylceramide by phagocytic processes. By yet undefined mechanisms, this process leads to tissue dysfunction that can result in fibrosis and scarring during the later stages of the disease.

\footnotetext{
* Correspondence: greg.grabowski@cchmc.org

'The Division of Human Genetics, Cincinnati Children's Hospital Research

Foundation, Cincinnati, OH 45229-3039, USA

Full list of author information is available at the end of the article
}

Some of these tissue changes have been attributed to "activation" of the engorged macrophages with subsequent release of inflammatory agents. Indeed, some Gaucher disease patients had increased levels of proinflammatory (i.e., TNF $\alpha$, IL-6, IL-8, and IL-1 $\beta$ ) and anti-inflammatory cytokines (i.e., CD14) in serum and/ or tissues [2-4]. TNF $\alpha$ production has been suggested as a response to glucosylceramide accumulation in Gaucher disease patients [2]. Serum levels of M-CSF, sCD14 (a macrophage activation marker), and IL-8 can also be increased and correlations have been made with the severity of Gaucher disease [3]. An in situ study of spleen from a Gaucher disease patient showed increased expression of anti-inflammatory mediators in macrophages, including CCL18, CD163, chitotriosidase, IL$1 \mathrm{Ra}$, and CD14 [5]. Such anti-inflammatory mediators are considered markers of alternatively activated macrophages $(\operatorname{aam} \phi)$ [6-10] and implicate secreted cytokines as pathophysiological agents in Gaucher disease. Such studies also suggest a central role of glucosylceramide
C Biomed Central

() 2011 Xu et al; licensee BioMed Central Ltd. This is an Open Access article distributed under the terms of the Creative Commons Attribution License (http://creativecommons.org/licenses/by/2.0), which permits unrestricted use, distribution, and reproduction in any medium, provided the original work is properly cited. 
in altered macrophage function as an initiator of the disease pathogenesis.

How the insufficiency of GCase activity and the subsequent metabolic disturbances related to glucosylceramide and other sphingolipids (GSLs) could lead to such inflammatory imbalances remains obscure. However, the consequent imbalances of ceramide, sphingosine, and sphingosine 1-phosphate in Gaucher disease could affect immunologic responses, inflammation and cell proliferation [11-13]. These and other studies implicate profound systematic pathophysiological changes rather than simple lipid accumulation as the basis of the disease [1] The pathologic manifestations of various organs suggest that the defective glucosylceramide hydrolysis and substrate accumulation in multiple organs affects numerous metabolic networks. Consequently, systematic transcriptome analyses could provide useful insights into the resultant molecular events underlying GCase deficiency and glucosylceramide storage as well as related tissue pathogenesis in Gaucher disease. In addition to visceral processes, some correlations of neuropathologic involvement with gene expression profiles in brains from neuronopathic Gaucher disease patients or Gba1 variant mice $[14,15]$ provide isolated cross-sectional views of the disease processes. However, they have not provided insight into the dynamic or sequential nature of such pathophysiological progression.

Here, viable Gba1 point-mutated mice, V394L/V394L (4L) and D409 V/null (9 V/null), were used to explore the temporal and spatial profiles of tissue and Gba1 mutation-related gene expression by genomewide mRNA microarrays and immunohistochemical analyses. Particular focus was on macrophage activation (classic and alternative) responses and IFN $\gamma$ regulated pro-inflammatory or IL-4 regulated antiinflammatory networks. These studies established a starting point for understanding the basis of the progressive pathophysiology in Gaucher disease at a molecular/tissue level.

\section{Results}

Phenotype of Gba1 V394L homozygotes (4L) and D409 V/ null $(9 \mathrm{~V} /$ null) mice

$4 \mathrm{~L}$ or $9 \mathrm{~V} /$ null mice appear phenotypically normal and have survived $\sim 2$ years. All mice have grossly normal behavior, reproduce, and show no gross evidence of CNS abnormalities. The residual GCase activity levels in visceral organs were $6-7 \%$ or $4-7 \%$ of WT in $4 \mathrm{~L}$ or $9 \mathrm{~V} /$ null, respectively [16]. By LC-MS/MS analyses, accumulations of glucosylceramide were detected in $9 \mathrm{~V} /$ null lung and liver as early as at $4 \mathrm{wk}$ (2- to 6-fold over the WT controls), and then progressed up to 33-fold during 12 to 28 wk and $>40$-fold at $52 \mathrm{wk}$ (Figure 1). In 4L mice, glucosylceramide levels in lung and liver were 2- to 3-fold increased at 4 or $52 \mathrm{wk}$, respectively (Figure 1). Numerous large storage cells were observed in $9 \mathrm{~V} /$ null lungs (Figure 2 ) and to a lesser extent in liver at 12,18 , and $28 \mathrm{wk}$. Such cells were much smaller and less numerous in $4 \mathrm{~L}$ lungs (Figure 2). The macrophage nature of storage cells was evidenced by their CD68 and F4/80 positivity (Figure 2).

\section{Differential gene expression in tissues from Gaucher mice} The RNA samples were from lungs and livers of $9 \mathrm{~V} /$ null and 4L mice at the ages of 4-, 12-, 18- and 28-wk. The probe sets for each gene in the mutant mice that showed significantly differential expression were compared with those from the strain background matched WT. In these mutant models, the altered probe signals ranged from 560 to 1806 of the 45101 total probes on the chip. For further analyses, the genes were assigned to the probe sets. At a false positive rate (FDR) of 0.01 , about $1.2-4 \%$ of total genes were significantly differentially expressed:

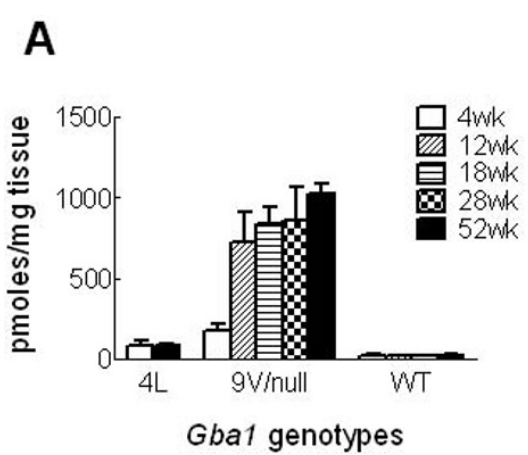

B

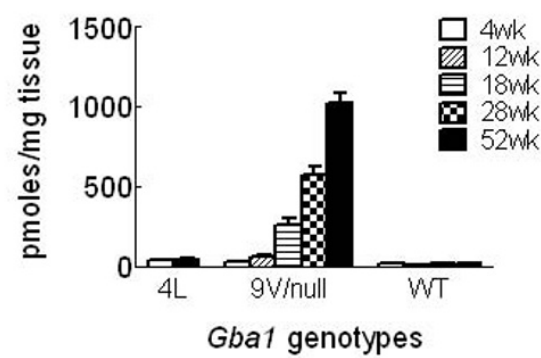

Figure 1 Glucosylceramide in $\mathbf{9}$ V/null and 4L mice. A: LC-MS/MS analyses showed an age dependent progressive accumulation of glucosylceramide in the lung of $9 \mathrm{~V} /$ null mice: 6-fold, 28- to 33-fold, and 40-fold greater than WT at 4, 12-28, and 52 wk, respectively. In the $4 \mathrm{~L}$ lung, there was $~ 3$-fold increase by 4 to 52 wk. B: Similar, progressive accumulation of liver glucosylceramide: 5-fold, 15-fold, 32-fold, and 46-fold greater than WT at 12, 18, 28, or 52 wk, respectively. Glucosylceramide levels in the liver of $4 \mathrm{~L}$ were 2-fold increased over the WT. 
1171 or 402 genes in lung or liver, respectively, of $9 \mathrm{~V} /$ null mice; 1375 or 406 genes were in lung or liver, respectively, of $4 \mathrm{~L}$ mice (Additional file 1). The differentially expressed genes in each tissue were segregated into 12 major functional groups with statistical significance across the two tissues in both mouse models to provide global profiles of gene expression. The functional categories include catalytic activity, cell death, cytoskeleton, immune response, intracellular signaling cascade, kinase activity, lipid metabolic process, lysosome, macrophage activation, response to stress, transcription, and transport (Table 1 and Additional file 2). In lung, both mouse models showed similar spectra of gene expression patterns for these functional groups, except genes for immune response and macrophage activation that were more highly altered in $9 \mathrm{~V} /$ null mice. In $9 \mathrm{~V} /$ null and $4 \mathrm{~L}$ livers, fewer functional groups (6 to 7 ) were significant in comparison with lung profiles (Table 1). Interestingly, genes for cell death did not reach significance in 4L liver, and genes for immune response were significant only in $9 \mathrm{~V} /$ null lung (Table 1). The macrophage activation genes were grouped as a functional category, because the macrophage is the hallmark of Gaucher disease, and large numbers of storage cells (macrophages) were observed in the lungs of 12-, 18-, and 28-wk old $9 \mathrm{~V} /$ null mice (Figure 2). The enrichment of differentially expressed gene categories was examined by comparing the percentage populating the various gene ontologies in these two mouse models across lung and liver from all time points. Among these 12 different functional categories, the composition of macrophage activation genes in $9 \mathrm{~V} /$ null lung was $10 \%$ of the total altered genes, and $6 \%$ in $4 \mathrm{~L}$ lung: these represent 1.7 -fold enrichment (Table 1). To correlate the gene functional category with their expression profile in Gba1 mutant mice, the 1171 significantly differentially expressed genes in $9 \mathrm{~V} /$ null lung were analyzed

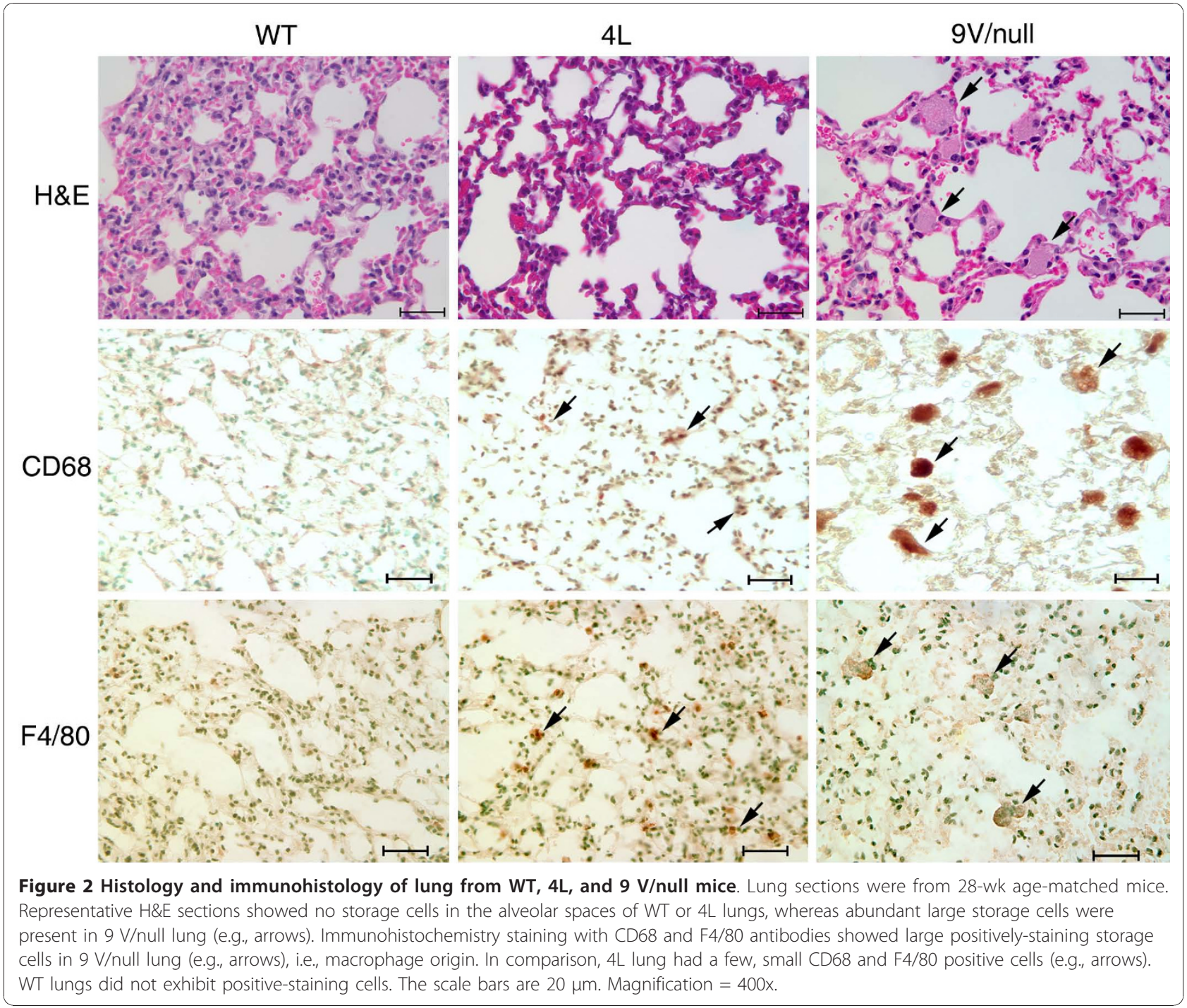


Table 1 Classification of significantly expressed genes in tissues of $9 \mathrm{~V} /$ null and $4 \mathrm{~L}$ mice

\begin{tabular}{|c|c|c|c|c|c|c|c|c|c|c|c|c|}
\hline \multirow[t]{3}{*}{ Categories } & \multicolumn{6}{|c|}{ Lung } & \multicolumn{6}{|c|}{ Liver } \\
\hline & \multicolumn{3}{|c|}{$9 \mathrm{~V} / \mathrm{null}$} & \multicolumn{3}{|c|}{$4 \mathrm{~L}$} & \multicolumn{3}{|c|}{$9 \mathrm{~V} / \mathrm{null}$} & \multicolumn{3}{|c|}{$4 \mathrm{~L}$} \\
\hline & No. & $\%$ & p-value & No. & $\%$ & p-value & No. & $\%$ & p-value & No. & $\%$ & p-value \\
\hline catalytic activity & 440 & $38 \%$ & 1.49E-06 & 527 & $39 \%$ & 4.24E-09 & 160 & $40 \%$ & 3.37E-04 & 157 & $39 \%$ & 2.61E-03 \\
\hline intracellular signaling cascade & 136 & $12 \%$ & 7.49E-10 & 166 & $12 \%$ & $2.40 E-10$ & 50 & $13 \%$ & 7.50E-04 & 46 & $11 \%$ & $1.24 \mathrm{E}-03$ \\
\hline kinase activity & 87 & $8 \%$ & $8.41 \mathrm{E}-04$ & 98 & $7 \%$ & $1.41 E-03$ & 34 & $9 \%$ & 8.07E-03 & 31 & $7 \%$ & 4.46E-02 \\
\hline lipid metabolic process & 66 & $6 \%$ & $7.62 \mathrm{E}-04$ & 73 & $5 \%$ & $1.43 \mathrm{E}-02$ & 37 & $9 \%$ & $1.22 \mathrm{E}-05$ & 30 & $7 \%$ & 7.71E-04 \\
\hline macrophage activation & 119 & $10 \%$ & $4.50 \mathrm{E}-04$ & 83 & $6 \%$ & $3.29 E-03$ & 24 & $6 \%$ & $5.74 \mathrm{E}-03$ & 26 & $6 \%$ & $6.93 \mathrm{E}-03$ \\
\hline transcription & 195 & $17 \%$ & $1.44 \mathrm{E}-03$ & 276 & $20 \%$ & 2.33E-08 & 83 & $21 \%$ & $2.50 \mathrm{E}-03$ & 76 & $19 \%$ & 4.17E-03 \\
\hline cell death & 75 & $7 \%$ & $1.36 \mathrm{E}-04$ & 89 & $7 \%$ & 3.83E-04 & 27 & $7 \%$ & 4.93E-02 & & & \\
\hline cytoskeleton & 78 & $7 \%$ & $3.92 \mathrm{E}-02$ & 87 & $7 \%$ & $5.96 \mathrm{E}-03$ & & & & & & \\
\hline lysosome & 29 & $3 \%$ & $1.91 \mathrm{E}-05$ & 27 & $2 \%$ & $1.43 E-03$ & & & & & & \\
\hline response to stress & 79 & $7 \%$ & $1.52 \mathrm{E}-03$ & 91 & $7 \%$ & $1.20 E-02$ & & & & & & \\
\hline transport & 219 & $19 \%$ & $2.14 \mathrm{E}-04$ & 255 & $19 \%$ & 8.03E-03 & & & & & & \\
\hline immune response & 54 & $5 \%$ & 4.68E-03 & & & & & & & & & \\
\hline
\end{tabular}

The functional categories with $p$-value $<0.05$ were considered significant by Fisher Exact Test.

No. $=$ number of genes.

The empty rows were not significant $(p>0.05)$.

by hierarchical clustering, and three clusters were revealed across all ages in the lung. Cluster 1 showed 407 genes with low expression (35\% of total 1171 genes) in 9 $\mathrm{V} /$ null and 4L lung across the 4- to 28 -wk age range when compared with the WT lung (Figure 3, cluster 1). These down-regulated genes were mainly in the functional categories of catalytic activity, cell death, intracellular signaling cascade, kinase activity, macrophage, and transcription (Additional file 3). Cluster 2 contained about 55\% of genes (647 from total 1171 genes) and showed differential degrees of up-regulation in the $9 \mathrm{~V} /$ null and 4L lung (Figure 3, cluster 2). Cluster 3 showed $10 \%$ of genes (117 from total 1171 genes) with high expression levels exclusively in $9 \mathrm{~V} /$ null lung (Figure 3, cluster 3). These same genes did not have distinct patterns in the $9 \mathrm{~V} /$ null liver or the $4 \mathrm{~L}$ lung and liver data sets (Figure 3, right panel). Two-dimensional hierarchical cluster analyses show mutation-type (4L lung vs. $9 \mathrm{~V} /$ null lung) and tissue type-related (lung vs. liver) global gene expression profiles. These highly expressed 117 unique genes in $9 \mathrm{~V} /$ null lung contained 40 that were macrophage activation genes. The others represented intracellular signaling (5), lipid metabolic process (9), catalytic activity (23), and transport (10) (Figure 4). These initial findings strongly indicated the involvement of macrophage activation genes in Gaucher disease and led to the focus on the expression profiles of macrophage activation related genes in $9 \mathrm{~V} /$ null lung.

\section{Expression profile of macrophage activation genes}

To explore the expression profile of macrophage activation, all 119 such genes (Table 1) were analyzed. At early stages of the disease ( $4 \mathrm{wk}$ ), $44 \%$ of these genes
(53/119) were significantly altered with 42 up- and 11 down-regulated in the $9 \mathrm{~V} /$ null lung (Additional file 4). As the disease progressed (12, 18 or $28 \mathrm{wk}), 81 \%$ (96/ $119)$ of the macrophage activation genes were significantly and consistently up-regulated, and 15\% (18/119) of these genes were down regulated in $9 \mathrm{~V} /$ null lung (Additional file 4). The genes with expressions significantly changed at 2 or 3 time points from 4 to $28 \mathrm{wk}$ were considered as consistently affected. Similar expression profiles were defined in $4 \mathrm{~L}$ lung where $88 \%(73 / 83)$ of such genes were altered at 4 wk with 48 up-regulated and 25 down-regulated. From 12 to 28 wk, 84\% (70/83) of the macrophage activation genes were affected with 43 up- and 27 down-regulated. The mean fold-change of these consistently up-regulated macrophage activation genes was $>3.5$-fold in $9 \mathrm{~V} /$ null lung and liver, whereas a 2.3-fold change was observed in the corresponding $4 \mathrm{~L}$ tissues (Figure 5 and Additional file 4).

Using the Ingenuity Analysis System and additional literature sources [5,8], 9 IFN $\gamma$-regulated pro-inflammatory and 9 IL-4-regulated anti-inflammatory genes were significantly expressed (fold change $\geq \pm 1.8$ ) from 12 to 28 wk (Table 2) in $9 \mathrm{~V} /$ null lungs with 5 pro-inflammatory genes significantly altered beginning at $4 \mathrm{wk}$ (Table 2). Most of these genes were cytokines/chemokines or their receptors, including CCL2, CCL3, CCL6, CCL9, CCL19, CXCL1, and CXCL12. Other genes included CD44 (a transmembrane glycoprotein related to cellular adhesion and migration) and the macrophage scavenger receptor 1 (Msr1). Several pro-inflammatory genes [IFN $\gamma$, interleukin 6 (IL-6), inducible nitric oxide synthase (NOS2) and TNF $\alpha$ ] did not meet the statistical significance (Bold genes in Table 2). 


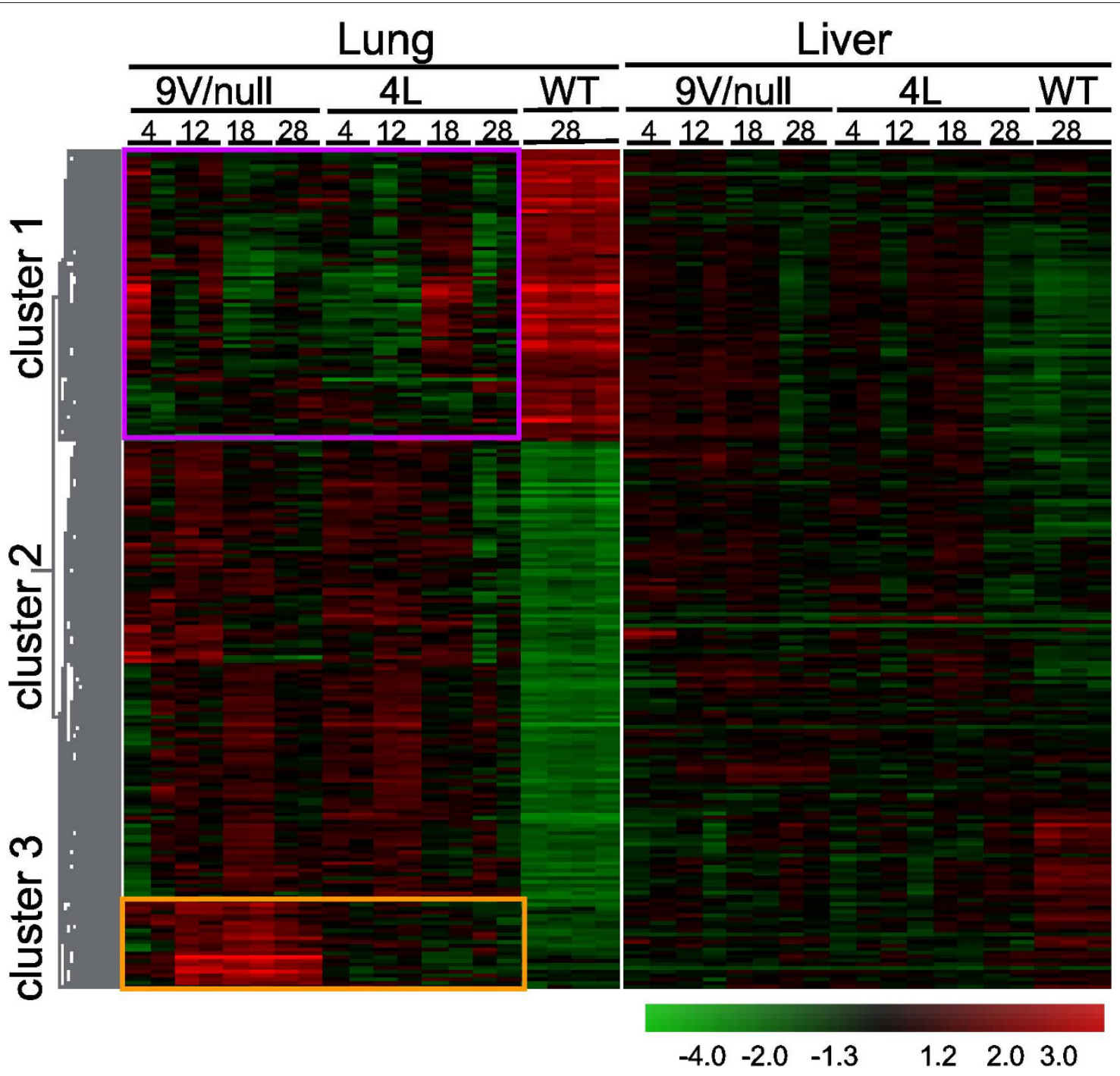

Figure 3 Hierarchical cluster analyses of differentially expressed genes in lung and liver of Gba1 mutant mice. The two-dimensional hierarchical clustering charts include 1171 genes differentially expressed in $9 \mathrm{~V} / \mathrm{null}$ lung, and the corresponding genes in $9 \mathrm{~V} / \mathrm{null}$ liver, and those in $4 \mathrm{~L}$ or WT lung and liver at ages of 4-, 12-, 18-, or 28-wk (see Materials and Methods). The expression patterns of duplicate chip data are displayed in adjunct lanes for each transcript. The heat map (Pearson correlation) displays gene group correlation patterns across all time points. Each column represents the general expression profile of 1171 genes at a time point. Each row represents a single gene across all time points. The intensities (red to green scale bar) are the log ratios, $\log _{2}(D / C)$, where $D$ and $C$ are the gene expression levels in the samples from $G b a 1$ mutant mice and WT controls, respectively, and indicate up- or down-regulated RNA expression. Clustering was performed by distance measurements. In cluster 1 are the 407 genes down-regulated in $9 \mathrm{~V} /$ null and $4 \mathrm{~L}$ lung compared to the corresponding genes in WT lung (genes listed in Additional file 2). In cluster 2 are the 647 genes had a variable degrees of up-regulation compared with WT controls. In cluster 3 (orange rectangle) is a group of 117 genes consistently up-regulated in the lung of 9 V/null mice at ages of 12- to 28-wk. These include 40 macrophage activation genes (see Figure 4).

To evaluate these genes, immunohistochemical analyses were conducted and the lipid-laden macrophages showed antibody positive signals (see below). The results show high expression of these four cytokine proteins in macrophages even though their respective RNA levels were relatively unchanged. Additional immunohistochemical analyses showed consistent positivity with antibodies to CCL2, CCL3, and CCL9; this was concordant with their RNA expression. Similar mRNA analyses showed that $6 \%$ of altered genes were in the macrophage activation category in $9 \mathrm{~V} /$ null liver or 4L lung and liver. However, none were pro-inflammatory genes (Table 2 and Additional file 5). These data support disease progression and tissue-type related profiles of pro-inflammatory gene expression in Gaucher disease. 


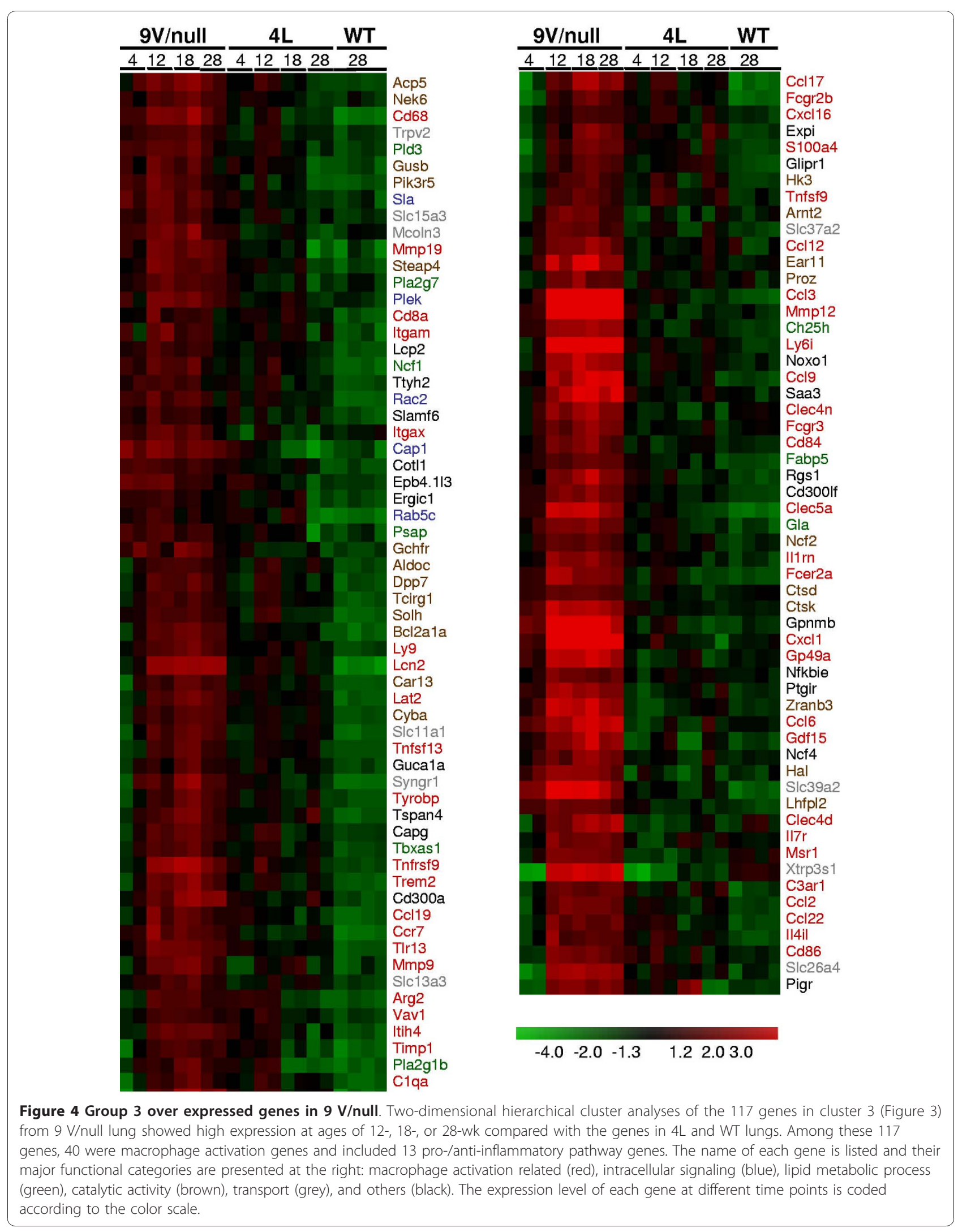




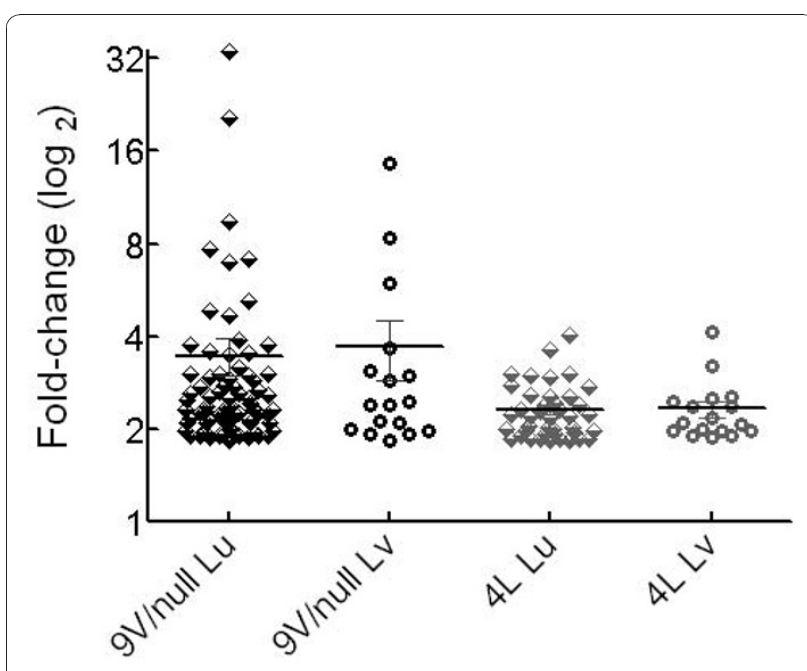

Gba1 mouse tissues

Figure 5 Consistently up-regulated macrophage activation genes in $\mathbf{9} \mathrm{V} /$ null and $\mathbf{4 L}$ mice. The expression values of each consistently ( $\geq 2$ time points from 12 to $28 \mathrm{wk}$ ) up-regulated macrophage activation genes in the lung (Lu) and liver (Lv) of $9 \mathrm{~V} /$ null and $4 \mathrm{~L}$ mice were plotted on the ordinate. The mean expression values (fold-change) of these genes in each tissue are indicated by a horizontal bar. The numbers of these genes were 96/ $119(81 \%)$ or $15 / 21(71 \%)$ in $9 \mathrm{~V} /$ null lung or liver, respectively; and $43 / 83(52 \%)$ or $14 / 21(67 \%)$ in $4 \mathrm{~L}$ lung or liver, respectively (Additional file 3). The median fold change for these gene expression values in $9 \mathrm{~V} /$ null lung and liver were higher than in the corresponding $4 \mathrm{~L}$ tissues.

In the IL-4 regulated pathway, 9 anti-inflammatory genes were up regulated in $9 \mathrm{~V} /$ null lung (Table 2). Two genes (Igh- 6 and Rentl $\alpha$ ) were up regulated by 4 wk and then continuously up regulated at 12 to $28 \mathrm{wk}$. The other seven anti-inflammatory genes were unchanged at 4 wk. These less significant changes in the anti-inflammatory genes at the age of 4-wk reflect the underdevelopment of alternatively activated macrophage features. With age (12-, 18- or 28-wk), all anti-inflammatory genes were consistently up regulated including the NOS2 counteracting enzyme arginase type II (Arg2), cytokine/chemokine CCL17/CCL22, immunoglobulin heavy chain 6 (Igh-6), IL-1 receptor antagonist (IL-1rn), and matrix metallopeptidase MMP9/12/19 (Table 2). Among these genes, MMP12 expression was exceptionally high (37- to 56-fold increased). MMP-12, macrophage elastase, functions to degrade extracellular matrix components, e.g., elastin, and is involved in acute and chronic pulmonary inflammatory diseases associated with an intense airway remodeling $[17,18]$. The antiinflammatory genes, e.g., IL-4, and the macrophage scavenger receptor CD163 did not meet statistical significance, but were positive by immunohistochemistry. With
$9 \mathrm{~V} /$ null liver mRNA, only three anti-inflammatory genes (Igh-6, IL-1rn and MMP12) were consistently up regulated (Additional file 5) indicating differential effects on the IL4-regulated anti-inflammatory pathway genes in lung and liver. In $9 \mathrm{~V} /$ null lung, these data show that the IL-4 regulated anti-inflammatory cytokines/mediators were also temporally and spatially altered and they were expressed in parallel with coordinate pro-inflammatory genes with disease progression.

The pro- and anti-inflammatory gene expression patterns were analyzed in the more attenuated $4 \mathrm{~L}$ model. In 4L lung, the percentage of altered macrophage activation genes was $\sim 50 \%$ of that in $9 \mathrm{~V} /$ null lungs (Table 1 ). No pro-inflammatory genes were altered in $4 \mathrm{~L}$ lungs during disease progression (Table 2), and the immunohistochemistry as well as routine histology were identical to WT. Only three anti-inflammatory genes (CCL17, Igh- 6 and Rentl $\alpha$ ) were consistently ( $\geq 2$ time points) up regulated in $4 \mathrm{~L}$ lung. The expression patterns of anti-inflammatory genes in liver of $4 \mathrm{~L}$ mice were similar to those in the 9 $\mathrm{V} /$ null mice. There were no pro-inflammatory genes significantly altered and only the anti-inflammatory genes, Igh-6, IL-1rn, or MMP12, were consistently up regulated in $9 \mathrm{~V} /$ null and $4 \mathrm{~L}$ liver (Additional file 5). In summary, the median expression values of pro-inflammatory and anti-inflammatory genes in $9 \mathrm{~V} /$ null lung were 2 -fold higher than that in $9 \mathrm{~V} /$ null liver and $4 \mathrm{~L}$ tissues (Figure 6). These data demonstrate the differential RNA expression of pro-inflammatory or anti-inflammatory cytokines/mediators and their correlation with type of mutations and tissues, and disease progression. The results also indicate a differential molecular pathophysiology in $9 \mathrm{~V} /$ null or 4L Gaucher disease mice that is likely related to the degree of storage cell infiltration and accumulation of glucosylceramide.

\section{Commonality of significantly expressed genes involved in macrophage activation}

To explore the commonality of affected global or macrophage activation genes between two tissues in Gba1 variant mice, comparative analyses were displayed as Venn diagrams. More than $50 \%$ of the altered genes globally in lung or liver were concordantly and significantly expressed in $9 \mathrm{~V} /$ null and $4 \mathrm{~L}$ mice (Figure 7A and $7 \mathrm{~B}$, Additional file 5). These common genes were distributed in all 12 functional categories. Similar results were obtained by commonality analysis of significantly expressed macrophage activation genes between tissues of both Gba1 mutant models. As shown, 50\% of macrophage activation genes in lung or liver of $9 \mathrm{~V} /$ null mice were similarly affected in 4L mice (Figure $7 \mathrm{C}$ and 7D). The intersection of macrophage activation genes in lung or liver from $9 \mathrm{~V} /$ null and 4L mice includes pro-/ anti-inflammatory cytokines, cytokine receptors, growth 
Table 2 Expression of pro- and anti-inflammatory macrophage activation genes in lungs of $9 \mathrm{~V} / \mathrm{null}$ and $4 \mathrm{~L}$ mice

\begin{tabular}{|c|c|c|c|c|c|c|c|c|c|c|}
\hline \multirow[b]{2}{*}{ Pathways } & \multirow[b]{2}{*}{ Symbol } & \multirow[b]{2}{*}{ Gene Name } & \multicolumn{4}{|c|}{$9 \mathrm{~V} /$ null } & \multicolumn{4}{|c|}{ 4L } \\
\hline & & & $\begin{array}{l}\operatorname{lu}_{\text {lk }} 4 \\
\text { kk }\end{array}$ & $\begin{array}{l}\text { lu_12 } \\
\text { wk }\end{array}$ & $\operatorname{lu}_{w k}$ & $\operatorname{lu}_{w k} 28$ & $\begin{array}{l}\operatorname{lu}_{\text {lu }} 4 \\
\text { wk }\end{array}$ & $\operatorname{lu}_{\mathrm{wk}}$ & $\operatorname{lu}_{w k}$ & $\mathrm{lu}_{\mathrm{wk}} \mathbf{2 8}$ \\
\hline \multirow{13}{*}{$\begin{array}{l}\text { IFN } \gamma \\
\text { regulated }\end{array}$} & IFN $\gamma^{*}$ & interferon gamma & 1.124 & 1.292 & 1.336 & 1.204 & 1.513 & 1.278 & 1.329 & 1.435 \\
\hline & CCL19 & chemokine (C-C motif) ligand 19 & 1.325 & 3.288 & 3.336 & 2.039 & 1.738 & 1.469 & 1.166 & 1.536 \\
\hline & $\mathrm{CCL}^{*}$ & chemokine ( $\mathrm{C}-\mathrm{C}$ motif) ligand 2 & 1.134 & 2.835 & 2.564 & 2.467 & 1.284 & 1.220 & 1.203 & 1.463 \\
\hline & $\mathrm{CCL}^{*}$ & chemokine ( $\mathrm{C}-\mathrm{C}$ motif) ligand 3 & 1.855 & 19.86 & 37.518 & 22.298 & 1.464 & 1.673 & 1.155 & 1.347 \\
\hline & CCL6 & chemokine (C-C motif) ligand 6 & 2.004 & 4.073 & 6.557 & 6.138 & -1.380 & -1.090 & -1.344 & 1.228 \\
\hline & CCL9* & chemokine ( $\mathrm{C}-\mathrm{C}$ motif) ligand 9 & 1.893 & 5.817 & 10.346 & 9.722 & 1.317 & 1.546 & 1.512 & 1.365 \\
\hline & CD44 & CD44 antigen & 3.176 & 4.971 & 2.155 & 2.387 & 1.060 & 1.156 & -1.045 & 1.294 \\
\hline & CXCL1 & chemokine (C-X-C motif) ligand 1 & 1.466 & 8.56 & 10.786 & 7.739 & 1.322 & 1.252 & -1.183 & 1.663 \\
\hline & CXCL12 & chemokine (C-X-C motif) ligand 12 & 2.65 & 2.991 & 1.923 & 1.874 & 1.679 & 1.334 & 1.130 & 1.030 \\
\hline & IL-6* & interleukin 6 & -1.249 & 1.189 & 1.029 & -1.009 & -1.080 & -1.261 & -1.262 & -1.106 \\
\hline & Msr1 & macrophage scavenger receptor 1 & 1.092 & 2.843 & 2.808 & 2.322 & 1.349 & 1.515 & -1.089 & 1.076 \\
\hline & NOS2* & $\begin{array}{l}\text { nitric oxide synthase } 2 \text {, inducible, } \\
\text { macrophage }\end{array}$ & 1.226 & 1.207 & -1.001 & 1.13 & 1.206 & 1.351 & -1.001 & 1.200 \\
\hline & TNF* & tumor necrosis factor & -1.096 & 1.036 & 1.279 & 1.337 & 1.184 & 1.384 & -1.008 & 1.451 \\
\hline \multirow[t]{11}{*}{ IL-4 regulated } & IL-4* & interleukin 4 & -1.074 & -1.007 & 1.135 & 1.253 & -1.071 & 1.286 & 1.107 & 1.367 \\
\hline & Arg2 & arginase type ॥ & 1.315 & 2.661 & 3.044 & 2.034 & 1.787 & 2.179 & 1.298 & 1.344 \\
\hline & CCL17 & chemokine (C-C motif) ligand 17 & 1.146 & 3.756 & 8.523 & 5.903 & 1.982 & 2.494 & 1.522 & 1.674 \\
\hline & CCL22 & chemokine (C-C motif) ligand 22 & 1.237 & 3.066 & 2.734 & 2.725 & 1.402 & 1.477 & 1.096 & 1.559 \\
\hline & CD163* & CD163 antigen & -1.029 & 1.013 & -1.446 & -1.391 & 1.173 & 1.142 & 1.234 & -1.335 \\
\hline & $\operatorname{lgh}-6$ & Immunoglobulin heavy chain 6 & 3.036 & 3.066 & 3.430 & 2.565 & 2.864 & 1.810 & 1.724 & 1.637 \\
\hline & IL-1rn & interleukin 1 receptor antagonist & 1.417 & 3.615 & 3.815 & 2.762 & 1.296 & 1.317 & 1.376 & 1.141 \\
\hline & MMP12* & matrix metallopeptidase 12 & 1.705 & 37.346 & 56.278 & 39.721 & 1.225 & 1.023 & -1.240 & 1.217 \\
\hline & MMP19 & matrix metallopeptidase 19 & 1.762 & 3.607 & 3.428 & 3.112 & 1.659 & 1.650 & 1.563 & -1.249 \\
\hline & MMP9 & matrix metallopeptidase 9 & 1.272 & 2.837 & 4.307 & 2.308 & -1.353 & 1.233 & 1.199 & 1.226 \\
\hline & Retnla & resistin like alpha & 1.920 & 2.229 & 2.480 & 3.800 & 2.796 & 1.538 & 2.536 & 1.840 \\
\hline
\end{tabular}

Note: The gene symbols in Bold were not significantly expressed in microarray analysis, but were positive on immunohistochemstry in 9 V/null lung. The numbers show Fold Change in gene expression. The numbers in Bold were significantly affected and satisfied with FDR ( $\leq 0.01)$ and Fold Change at $\geq \pm 1.8$. Genes with * sign were positive on immunohistochemistry. wk = week.

factors, and MHC II molecules (Additional file 5). All the matched macrophage activation genes in the intersection were concordantly up or down regulated in both lung and liver of $9 \mathrm{~V} /$ null and $4 \mathrm{~L}$ mice. These data suggest a common basic pathway of macrophage activation genes in multiple tissues of Gbal mutated mice. In the lung of the $9 \mathrm{~V} /$ null and $4 \mathrm{~L}$ models, all genes for antigen processing related to MHC II and some complement components were up-regulated (Additional file 5). The effect of MHC on cytokine production has been shown to be particularly important in resistance of mice to intracellular pathogens [19]. These data imply that GCase deficiency and resultant substrate accumulation stimulated multiple immune response genes. The above analyses demonstrate that substantial numbers of macrophage activation genes were significantly affected in Gba1 variant mice, most of them were up-regulated and concordant with the disease progression from 12 to $28 \mathrm{wk}$, many were shared among tissues, but some were more tissue specific. Although the molecular cascades in macrophage activation are not yet known, the tissue-/ mutation-type and disease progress correlated profiles of macrophage activation-related genes suggest common temporally and spatially regulated mechanisms in the pathophysiology of Gaucher disease. The expression profiles of these genes also indicated macrophage activation in Gbal variant mice with significant heterogeneity between the tissues and mutation types.

\section{Effects of genetic background on mRNA profiles}

The genetic backgrounds of $9 \mathrm{~V} /$ null (FVB and C57BL/ 6J-129SvEvBrd) and 4L (C57BL/6J-129SvEvBrd) were slightly different, since the $9 \mathrm{~V} /$ null was generated by crosses of $9 \mathrm{~V} / 9 \mathrm{~V}$ (C57BL/6J-129SvEvBrd) with null/ WT (FVB) mice. To validate the macrophage gene expression profile and evaluate effects of the FVB strain on gene expression, FVB WT data sets ( 2 chips at 4 different time points each tissue) were run using the same methods and standards. A total of 48 chip sets (each 8 chip data from $9 \mathrm{~V} /$ null lung and liver, $4 \mathrm{~L}$ lung and 


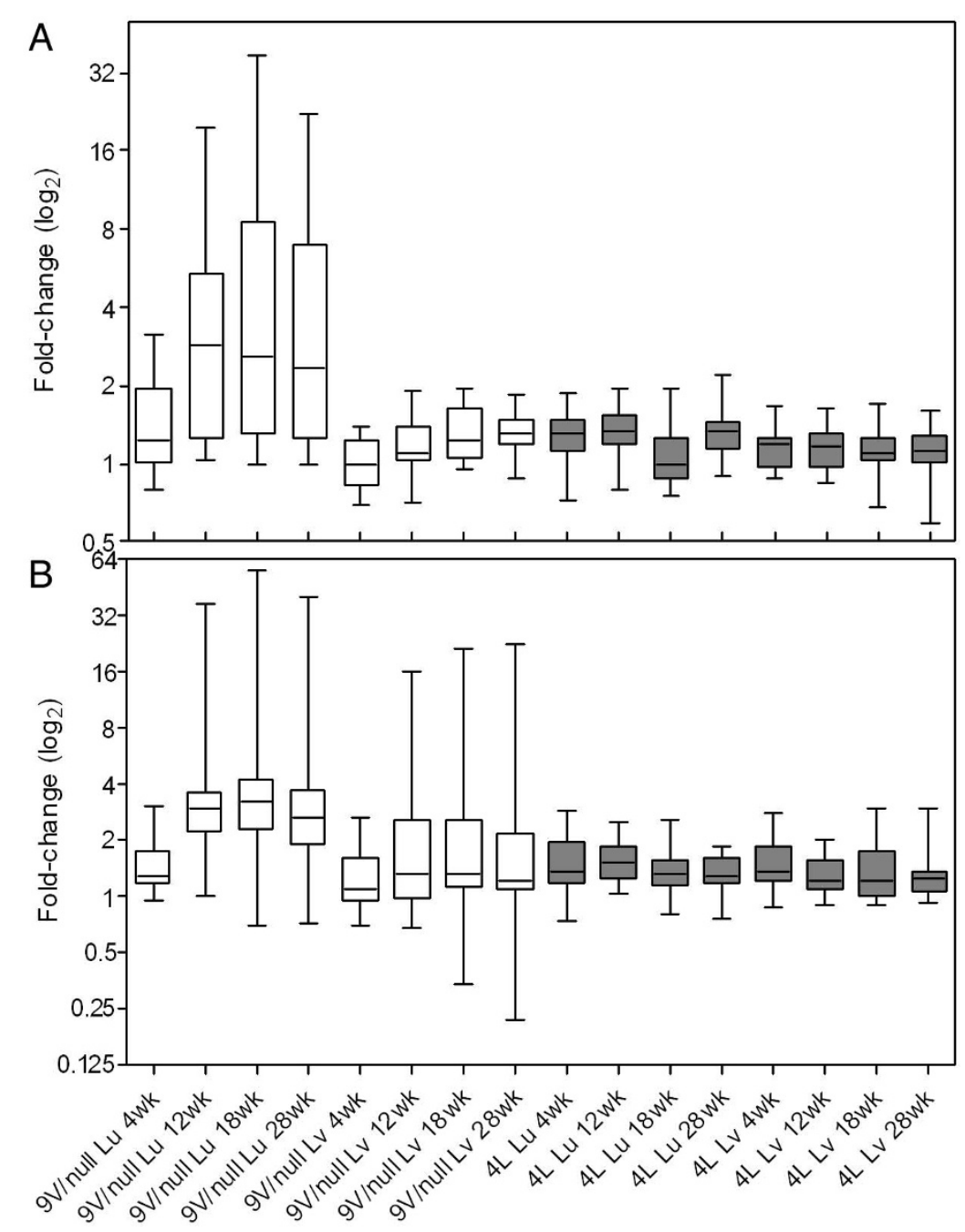

Figure 6 Time course of expression profiles of pro-inflammatory (A) and anti-inflammatory (B) genes in $9 \mathrm{~V} /$ null (white) or $4 \mathrm{~L}$ (grey) mice. The box plots of fold change (log2) show the median value of fold change of genes in each group (horizontal bars). The upper and lower boundaries of the boxes indicate the $75^{\text {th }}$ and $25^{\text {th }}$ percentile. The whiskers indicate the minimum and maximum of data set. The median fold change in the pro-(A) and anti-(B) inflammatory genes of $9 \mathrm{~V} /$ null lung showed a steep increase from 4 to 12 to 28 wk that paralleled those in $9 \mathrm{~V} /$ null livers. The expression levels of these same genes in $4 \mathrm{~L}$ lung and livers were lower and nearly constant over the time course of the analyses.

liver, and FVB WT lung and liver) were loaded into Partek Genomics Suite 6.4, and the data were normalized and analyzed (see Methods). FDR was set at 0.01 and fold change was set at \pm 1.8 for significance.

The numbers of significantly expressed genes in $9 \mathrm{~V} /$ null lung based upon the WT controls from these two different genetic backgrounds are as follows. With the FVB WT as control data set, 910 genes with significantly altered expression were selected. Among them, 10\% (90/910 genes) were macrophage activation genes and 1.6\% (15/ 910) were pro-/anti-inflammatory genes (Additional file 6 and Additional file 7 Table S1). The commonality of macrophage genes selected based upon different genetic background was also analyzed. Among 90 macrophage genes $\left(\mathrm{FVB}_{8 \text { chip }}\right), 52 \%$ (47 genes) were the same as with genetic matched controls (FVB/C57BL/6J-129S $\left.\mathrm{v}_{\text {chip }}\right)$. Also, $83 \%$ of INF $\gamma / \mathrm{IL}-4$ regulated pathway genes were shown to have similar gene expression profiles using either of the two genetic backgrounds. Although some variation exists in the selected genes and their expression significance, the macrophage activation genes, including INF $\gamma$ and IL-4 pathway genes, were identified as a major functional group using either strains.

\section{Validation of selected mRNA expression}

The genes identified by microarray analyses were selectively validated by real-time RT-PCR of the same pooled RNA as used for chip analyses. Primer sets for CCL9, 


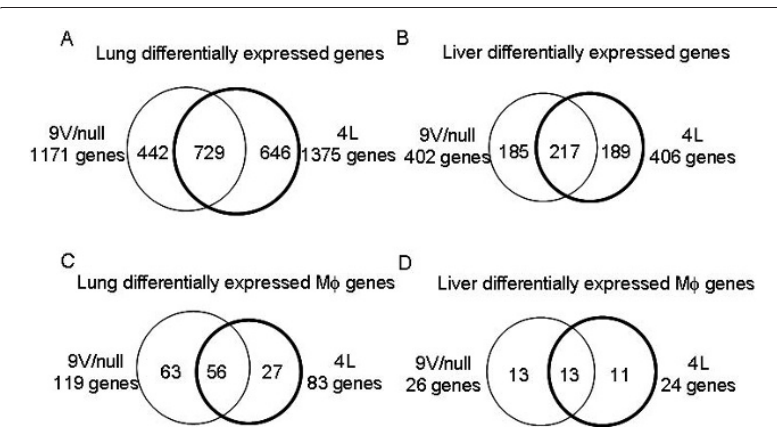

Figure 7 The commonality and uniqueness of significantly differentially expressed genes ( $A$ and $B$ ) and macrophage activation genes ( $C$ and $D$ ) in lungs ( $A$ and $C$ ) and livers ( $B$ and D) from $9 \mathrm{~V} /$ null and $4 \mathrm{~L}$ mice. Venn diagrams show the absolute number of differentially expressed genes in $9 \mathrm{~V} /$ null or $4 \mathrm{~L}$ tissues. Among the differentially expressed genes, 729 in lung (A) and 217 in liver (B) were common to $9 \mathrm{~V} /$ null and $4 \mathrm{~L}$ mice. In comparison, the uniquely expressed genes in $9 \mathrm{~V} /$ null or $4 \mathrm{~L}$ lungs were 442 or 646, respectively; and 185 or 189 in $9 \mathrm{~V} /$ null or 4L livers. In (C and D) the Venn diagrams represent the number of differentially expressed macrophage activation genes in $9 \mathrm{~V} /$ null and $4 \mathrm{~L}$ lungs (C) and livers (D). Among these genes, 56 in lungs and 13 in livers were found common to $9 \mathrm{~V} /$ null and $4 \mathrm{~L}$ mice. The numbers of uniquely expressed genes in $9 \mathrm{~V} /$ null or $4 \mathrm{~L}$ lungs were 63 or 27 , respectively; 13 or 11 in $9 \mathrm{~V} /$ null or $4 \mathrm{~L}$ livers. The expression values of these genes are in Additional file 4.

Msr1, CCL17, and MMP12 were used in duplicate assays and $\beta$-actin RNA was used as an internal control. The results show similar patterns of cytokine gene expression to those obtained by chip analyses. The fold-change values obtained with real-time RT-PCR were 2- to 4-fold higher than those from chip analyses (Figure 8). This reflects inherent differences of the two methods.

\section{Immunohistochemical studies of the macrophage activation related genes}

Histological and immunohistochemical studies were conducted with lung and liver sections from $9 \mathrm{~V} /$ null and 4L mice to correlate gene expression patterns with protein levels. As shown, numerous large storage cells were observed in $9 \mathrm{~V} /$ null lung with positivity for the surface antigens, CD68 and F4/80 (Figure 2). CD68 RNA also was elevated in lungs (3.3-7.2 fold) and livers (2.0-4.8 fold) of $9 \mathrm{~V} /$ null mice at 12 to $28 \mathrm{wk}$, but they had no significant alteration in 4L lung and liver (Additional files 1 and 4). This result would be expected because of the large number of storage cells in the lungs of $9 \mathrm{~V} /$ null mice. Immunohistochemical staining with CD68 antibody showed high intensity CD68-positive storage cells in the lung (Figure 2, middle) and liver (not shown). CD68-positive cells were quantified and showed 205 and 241 per 20 representative fields $(40 \times)$ in the lung from two $9 \mathrm{~V} /$ null mice. A few small sized
CD68-positive cells were observed in WT lung at $28 \mathrm{wk}$ (Figure 2, middle). In 4L lungs, multiple (268 \pm 38 , 40× field, $\mathrm{n}=10)$ small CD68-positive macrophages were present at 28 wk (Figure 2, middle). F4/80 (Emr1) RNA signals were within \pm 1.8 -fold range in all $9 \mathrm{~V} /$ null and 4L tissues. By immunohistochemistry, F4/80 positive macrophages were 190 and 174 per 20 fields $(40 \times)$ in the lung of two $9 \mathrm{~V} /$ null mice. The qualitative staining intensity of F4/80-positive storage cells was weak to medium compared to that of CD68 positive cells in lung of $9 \mathrm{~V} /$ null mice (Figure 2, bottom).

Macrophage activation in $4 \mathrm{~L}$ and $9 \mathrm{~V} /$ null mice was evaluated using antibodies to cytokines corresponding to genes with differential RNA expression. Antibodies to pro-inflammatory cytokines INF $\gamma$, IL-6, NOS2 (Figure 9), CCL2, CCL3, CCL9 (Figure 10), and TNF $\alpha$ (Figure 11) stained storage cells intensely in lungs from $9 \mathrm{~V} /$ null mice and were quantified microscopically (see below). Some NOS2 positive cells were present in $4 \mathrm{~L}$ lungs, but the antibodies to the other cytokines were negative (Figure 9). The RNA expression level of INF $\gamma$, IL-6, NOS2 and TNF $\alpha$ in $9 \mathrm{~V} /$ null lungs did not satisfy the $\mathrm{FDR} \leq 0.01$, but the respective proteins could be detected by immunohistochemistry at 12 to $28 \mathrm{wk}$. By dual immunofluorescence staining, many TNF $\alpha$ signals co-localized with CD68 signals in $9 \mathrm{~V} /$ null lung; the TNF $\alpha$ intensity was relatively weak compared with CD68 signal (Figure 11, merged pictures). TNF $\alpha$ signals in $4 \mathrm{~L}$ lung at 12 and 18 wk were also positive, but with lower intensities and in fewer cells compared with those in $9 \mathrm{~V} /$ null lung at $28 \mathrm{wk}$ (data not shown).

In $9 \mathrm{~V} /$ null lungs, positive signals were also evident for the anti-inflammatory cytokines, IL-4, MMP12, and Arg2 (Figure 12), and CD163 (Figure 13). As with some pro-inflammatory genes, the RNA expression of IL-4 or CD163 genes in $9 \mathrm{~V} /$ null lungs did not satisfy the FDR 0.01 , but their protein levels were assessed by immunohistochemistry or immunofluorescence staining at 12 to $28 \mathrm{wk}$. The signals of IL-4 positive macrophages were relatively weak in lung of $9 \mathrm{~V} /$ null at $28 \mathrm{wk}$, and no signals were detected in WT and 4L lung (Figure 12). The staining intensity with Arg2 and MMP12 antibody was at intermediate levels in $9 \mathrm{~V} /$ null lung at $28 \mathrm{wk}$ (Figure 12). Arg2 positive cells also were observed in the lung of 4L mice at $28 \mathrm{wk}$. CD163 signals were significant in lung of $9 \mathrm{~V} /$ null mice compared with the signals in WT and 4L tissues (Figure 13), and these mostly colocalized with CD68 signals. In 4L mouse lung, the macrophages were small. The antibody positive macrophages for CCL2, CCL3, CCL9, IL-6, NOS 2 , IL-4, or MMP12 were quantified as above and showed 79 to 122 per 20 fields in $9 \mathrm{~V} /$ null lung (Figure 14); INF $\gamma$ or Arg2 antibody positive cells numbered 220 or 190 per 20 fields. The intensity of each antibody staining at 4 to 28 

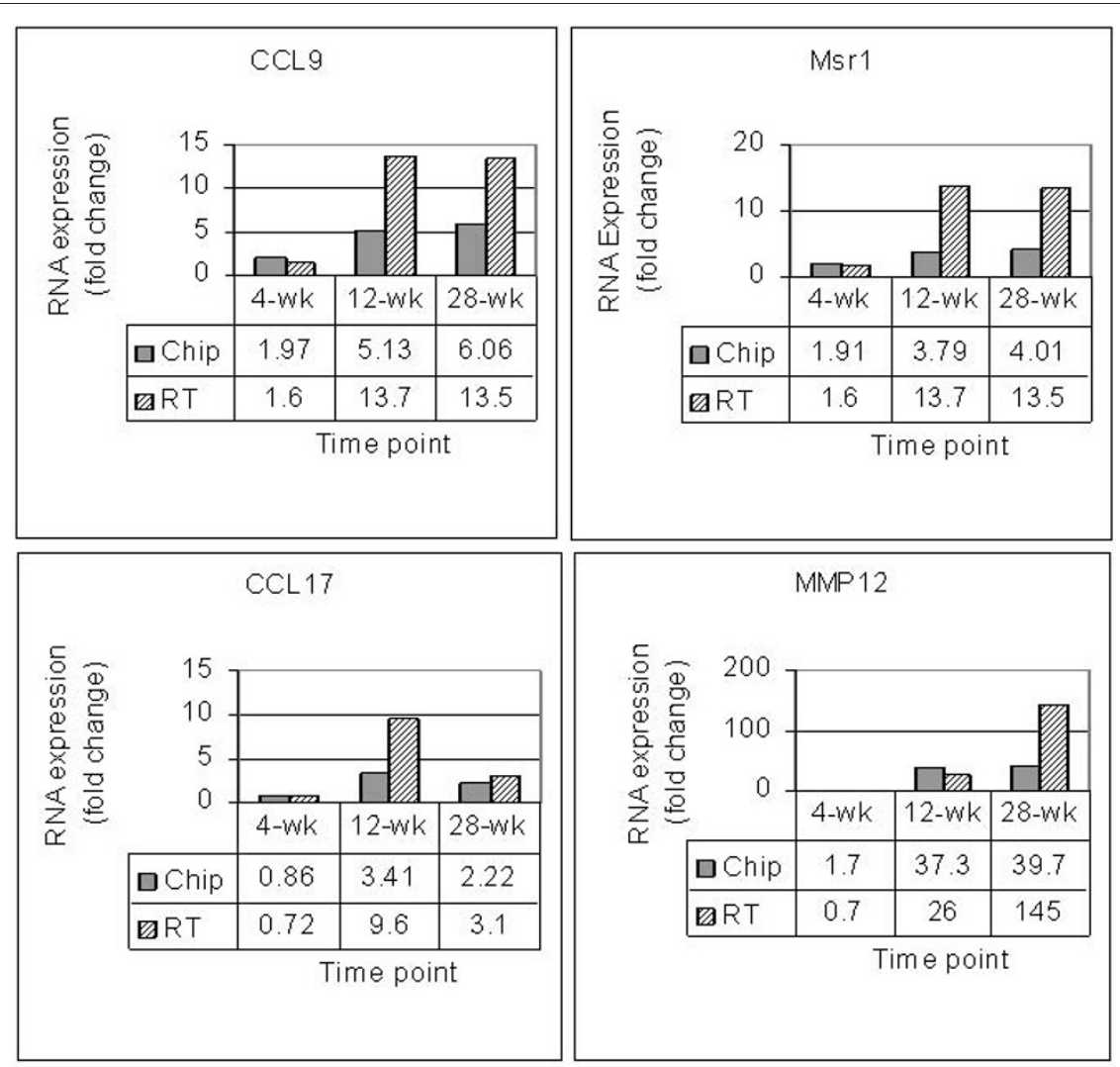

Figure 8 RT-PCR verification of selected cytokine gene expression levels. Pooled lung RNA samples used for microarray analyses were used for RT-PCR of CCL9, Msr1, CCL17, MMP12, and $\beta$-actin. Signals for these genes from $9 \mathrm{~V} /$ null and WT lung RNAs were normalized to $\beta$-actin RNA. The average values (fold changes) for RT-PCR (hatched bar) represent the ratios of $9 \mathrm{~V} /$ null and WT at each time point (X-axis). The fold change values were from 2 separate triplicate experiments. The comparative fold changes (Table 1) for each respective gene from the microarray analyses are shown as grey bar.

wk showed a concordant pattern with the RNA expression profile. These studies show differential expression of macrophage activation related genes in the various mice with Gba1 mutations that were nearly cell specific.

\section{IFN $\gamma$ and IL-4 regulated pathways and gene expression networks}

PathwayArchitect 2.0.1 (Stratagene, La Jolla, CA) and Ingenuity Pathways Analysis (Ingenuity Systems, Inc.) were conducted to summarize the potential interactions of pro-inflammatory or anti-inflammatory cytokines/ mediators based on the RNA microarray data and immunohistochemical data (Figure 15). Nine of 13 macrophage pro-inflammatory genes were significantly affected at $4 \mathrm{wk}$ (Figure 15A, left, red or orange color). Beginning at $12 \mathrm{wk}$, all 13 pro-inflammatory genes were significantly up regulated at the RNA or protein levels, and then remained at up-regulation until $28 \mathrm{wk}$ (Figure 15A). Most of anti-inflammatory genes in the 9 $\mathrm{V} /$ null lung were not changed at 4 wk (Figure 15B, white color), but were at 12 to $28 \mathrm{wk}$ (Figure 15B, red or orange color). Interestingly, the up-regulation of IL-4 was only detected at $28 \mathrm{wk}$. This pro- or anti-inflammatory pathway model summarizes a significant coordination and interaction of pro- or anti-inflammatory cytokines/mediators in the disease process.

A potential global gene expression network and a cascade regulation initiated by macrophage activation genes were evaluated using PathwayArchitect 2.0.1 and Ingenuity Pathways Analysis programs. A total 391 significantly expressed genes in $9 \mathrm{~V} /$ null and 345 genes in $4 \mathrm{~L}$ lungs were connected in the IFN $\gamma$ - or IL-4-regulated pro-/anti-inflammatory pathway (Figure 16A and 16B). This network was built with a high confidence index of direct and indirect interactions. In this cascade network, IFN $\gamma$ - and IL-4-regulated pro-/anti-inflammatory genes as core genes (red) connected with many different functional pathways through key genes. These key genes are significantly connected to the next group genes in the cascade of network (connectivity $>1000$ ) [20]. The included main gene groups in each cascade regulation were for transcription (green), kinase activity (blue), cell 


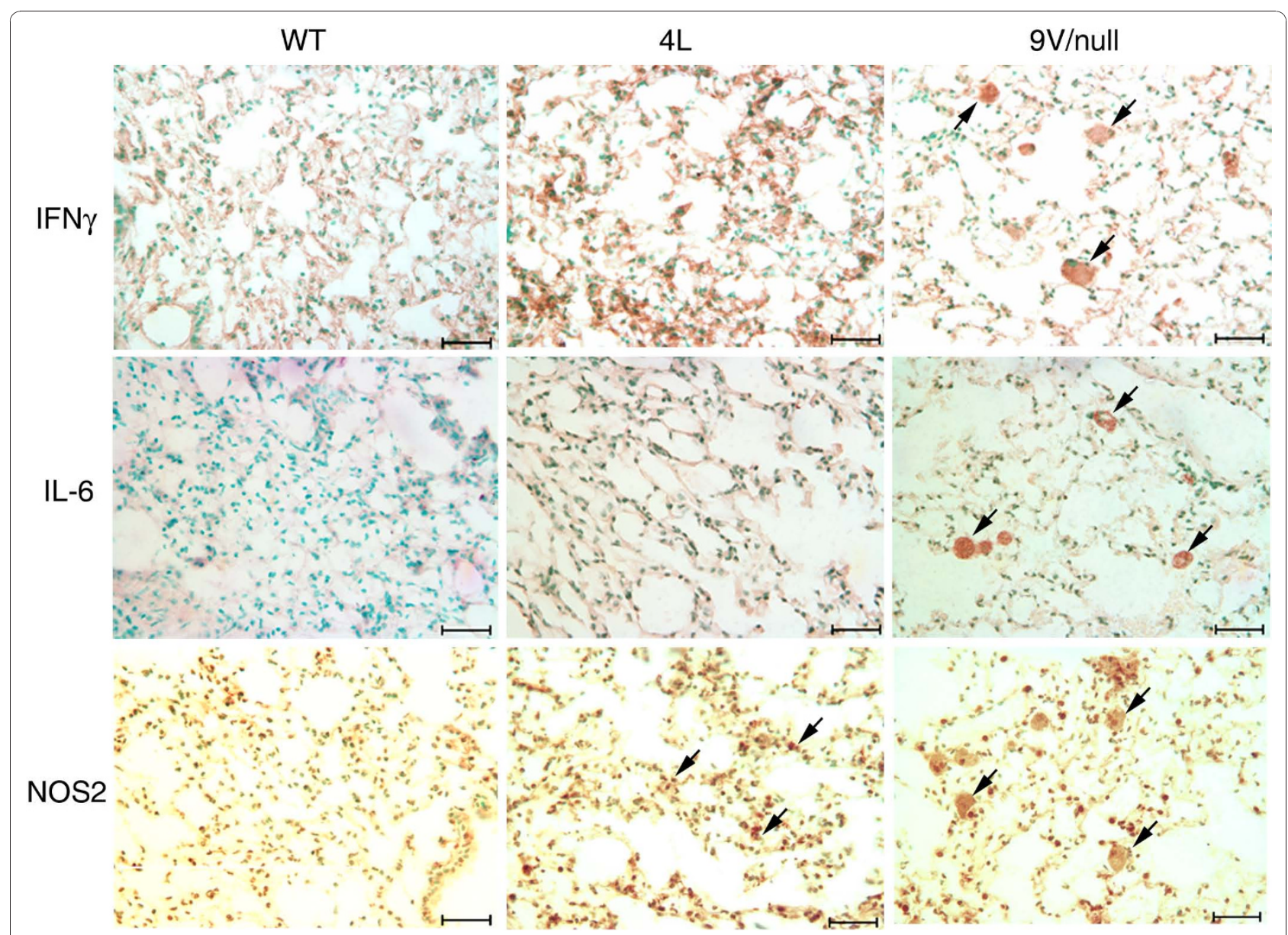

Figure 9 Expression of IFNg and pro-inflammatory cytokines in lung macrophages of WT, $4 \mathrm{~L}$, and 9 V/null mice. Lung sections were from 28-wk age-matched mice. Large storage cells in $9 \mathrm{~V} /$ null lungs were positive for IFNg, IL-6, and NOS2 (arrows). In 4L lung, a few, small NOS2 signal positive cells present (arrows). WT lungs did not exhibit positive staining. The scale bars are $20 \mu \mathrm{m}$. Magnification $=400 \times$.

death (purple), and signal transduction (yellow) (Additional file 8).

\section{Discussion}

The genome-wide transcriptome data presented here demonstrate genotype and tissue-type related gene expression patterns in $9 \mathrm{~V} /$ null and $4 \mathrm{~L}$ mice that are analogues of human Gaucher disease. Interestingly, the percentage of functional categories containing dysregulated RNAs was similar across all $9 \mathrm{~V} /$ null or $4 \mathrm{~L}$ tissues, except for the macrophage activation genes that showed 2-fold enrichment in $9 \mathrm{~V} /$ null lung, the most extensively involved organ (Table 1). Another identified group was that for immune response genes, which were altered only in $9 \mathrm{~V} /$ null lung. Among the 54 immune response genes, 47 overlapped with the macrophage group. Since histological analyses did not find obvious $\mathrm{T}$-cell and B-cell infiltration in $9 \mathrm{~V} /$ null lung, these immune responses likely emanated from macrophages. Macrophage activation in $9 \mathrm{~V} /$ null lung was also supported by hierarchical clustering analysis in which the 117 genes in cluster 3 (Figure 3) were exclusively expressed in $9 \mathrm{~V} /$ null, rather than in $4 \mathrm{~L}$ lung; a third of these were macrophage activation genes (Figure 3, highlighted region). These results indicate significant involvement of macrophage activation genes in $9 \mathrm{~V} /$ null lung, which was concordant with the extensive macrophage infiltration in the lungs. Moreover, the complementary histopathological studies showed that the nature of macrophage activation was not uniform between tissues or within macrophages in a specific tissue. These data support the concept of a variety of dysregulated macrophages that are tissue and disease state dependent as a dynamic component of the Gaucher disease/glucosylceramide storage pathophysiology.

Engorged macrophages are a hallmark of Gaucher disease, and these cells were differentially activated in tissues of $9 \mathrm{~V} /$ null and $4 \mathrm{~L}$ mice at the mRNA, cellular, and immunohistochemical levels. The progressively increasing sizes and numbers of macrophages in visceral 


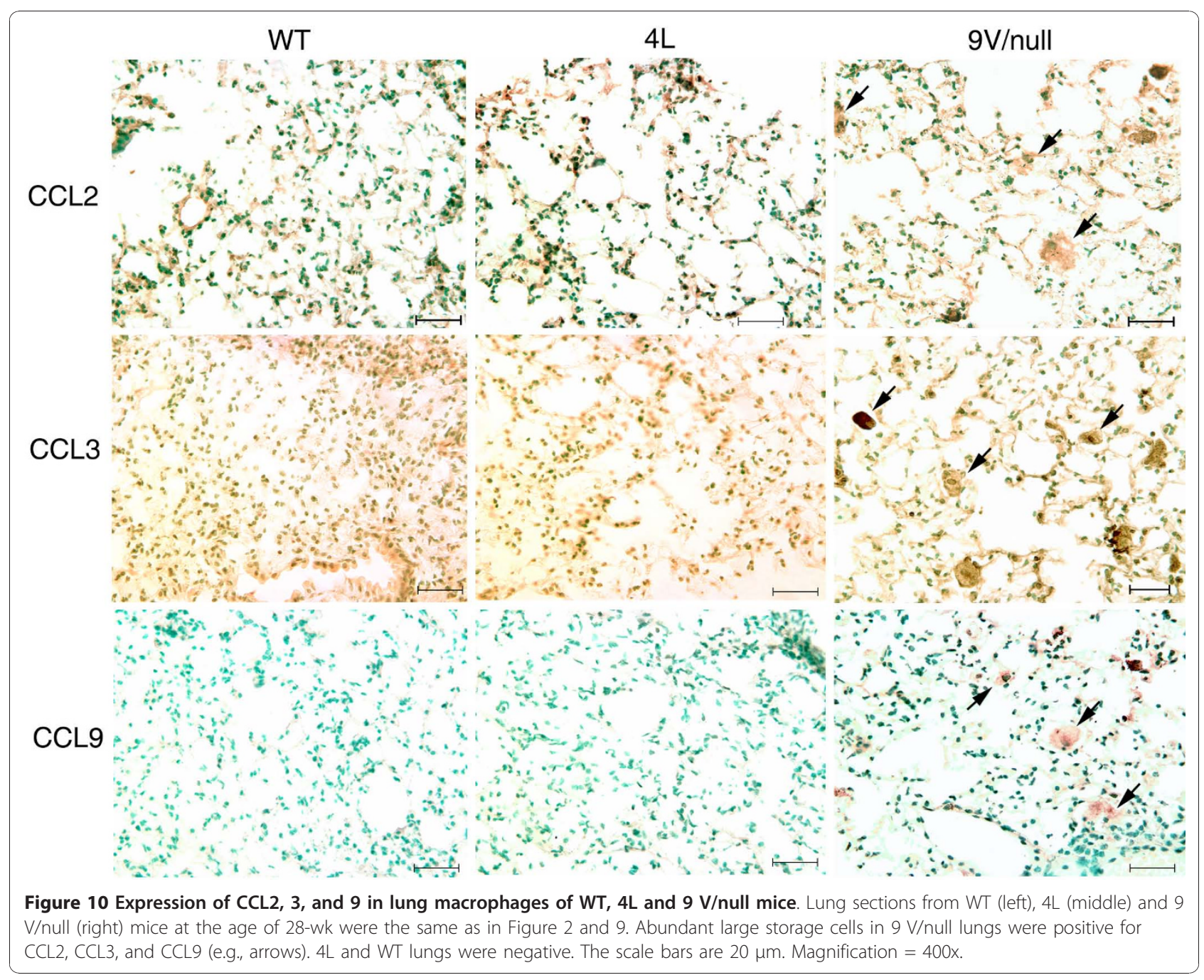

organs of Gba1 variant mice, because of the lipid storage, was particularly evident in lungs of $9 \mathrm{~V} /$ null mice from 12 to 28 wk (Figure 1). Immunohistochemistry with the antibodies to selected IFN $\gamma$-regulated proinflammatory and IL-4-regulated anti-inflammatory cytokines showed that these cytokines were expressed in lung macrophages, but not in lung epithelial cells, i.e., there were pro- and anti-inflammatory responses (or activation) of the lipid-laden macrophage. Also, such analyses showed significant expression of the IFN $\gamma$ protein in lung macrophages of $9 \mathrm{~V} /$ null mice at 12 and 28 wk (Figure 9), but lesser expression in liver. These expression patterns were concordant with the differential activation of macrophages in these tissues as was evident by both microarray and morphologic data. In addition, IFN $\gamma$ and its regulated pathway genes were less aberrant in tissues of the 4L mice, a more attenuated model, as ascertained by RNA or protein analyses. These results implicate pro-inflammation as a primary pathophysiological mechanism in Gaucher disease, as well as the degree of alterations in this pathway in the severity of Gaucher disease involvement. The production and secretion of cytokines from storage macrophages can be the important factors for the extracellular matrix components and function as they influence the interaction of surrounding macrophages with phagocytotic or endocytotic ligands and propagate the pathophysiology [21].

IFN $\gamma$ is a potent activator of macrophages and induces the expression of $>300$ genes, including those in the inflammatory mediator/chemokine pathway [22]. Also, activated macrophages can be a significant source of IFN $\gamma$ [23-25]. Importantly, IFN $\gamma$ inhibits macrophage proliferation and protects them from apoptosis [26], thereby prolonging their survival within inflammatory loci [27]. Here, the RNA expression levels of IFN $\gamma$, IL-6, NOS2, and TNF $\alpha$ were not significantly increased $(F D R=0.01)$, but their protein levels were specifically 


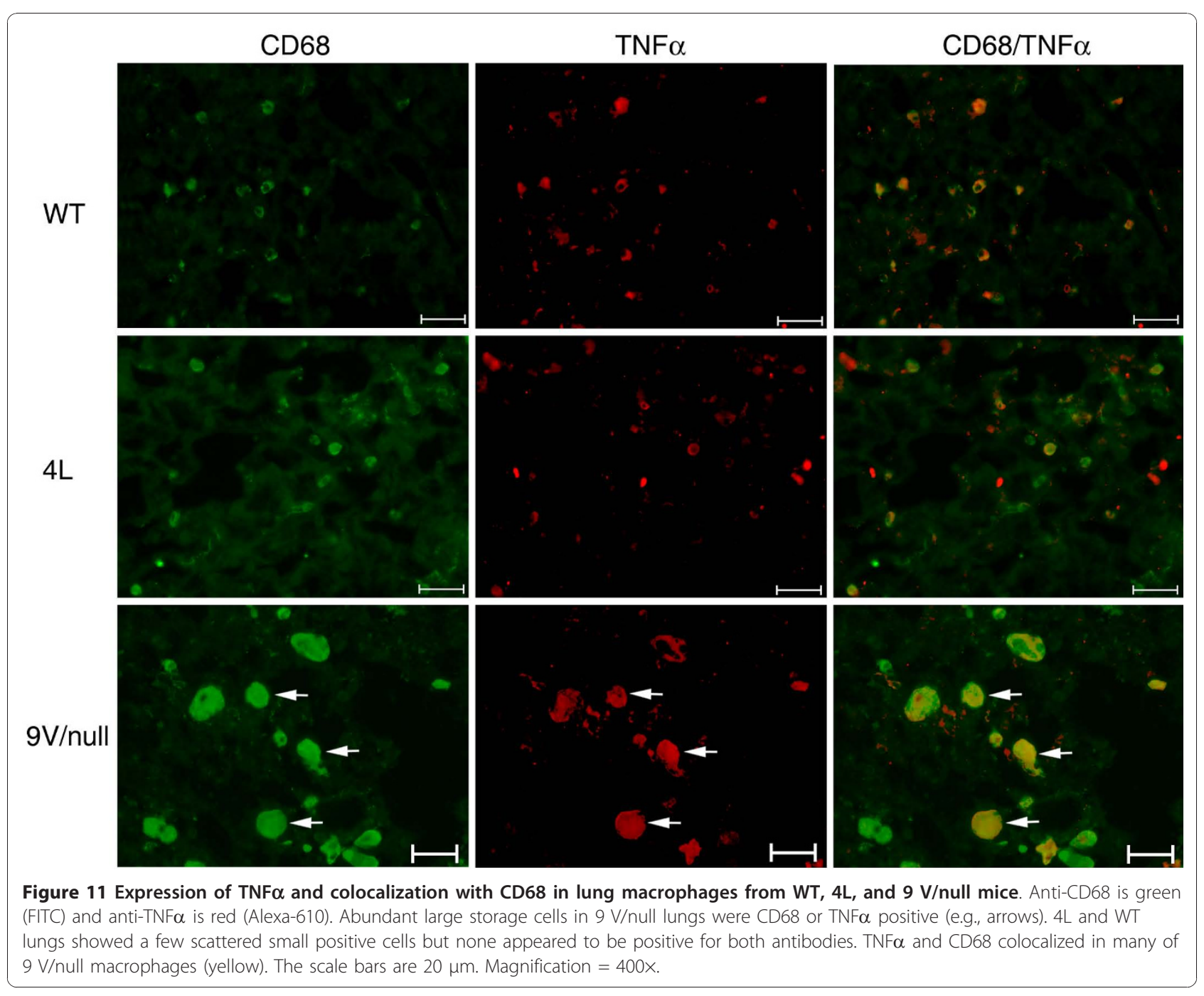

and highly expressed in the large lung macrophages. This observation indicates that the expression of these proteins and RNAs could be missed in whole tissue homogenates in which there may be large dilutional effects, if expression is restricted to specific cell types that make up a small percentage of total cells, e.g., macrophages. Importantly, 12 other cytokines are in the IFN $\gamma$ pathway and could be downstream modulated by this cytokine. For example, IFN $\gamma$ can induce TNF $\alpha$ and NOS2, and has differential effects on several individual chemokine genes [8] that provide for selective stimulus sensitivity in mediating restricted pattern of chemokine gene expression. Transcripts for CXCL1/12 and the CCL chemokines (CCL2, 3, 6, 9 or 19) can be enhanced by Th1-related inflammatory mediators including IFN $\gamma$, IL-6, TNF $\alpha$, or LPS $[28,29]$ as well as modulating the effects of each other (Figure 15). The outcomes of such interactions lead to a cascading cytokine pro-inflammatory dysregulation that propagates Gaucher disease.
Indeed, TNF $\alpha$ is a major regulator of chemokine gene expression, e.g., CXCL2, CCL3 and IL-6 [30-37]. The finding here that TNF $\alpha$ protein was up regulated (Figure 11) implicates its downstream cytokine network during Gaucher disease progression. Also, cytokines, e.g., CCL3, act synergistically with other macrophage chemokines [38] to maintain the pro-inflammatory reactions.

Pro-inflammatory cytokines play a critical role in macrophage/leukocyte recruitment and adhesion [39-42] and they recruit new macrophages to involved tissues via this cytokine network. Under the stimulus of accumulating glucosylceramide and other glucolipids, such a positive feedback macrophage-cytokine-macrophage cycle can be envisioned to expand and promote progression and the recruitment of additional pro-inflammatory cytokines/mediators networks (Figure 15). The progressive cascade is schematically shown in Figure 15 in which numerous interacting cytokines and chemokines are progressively up-regulated during disease 


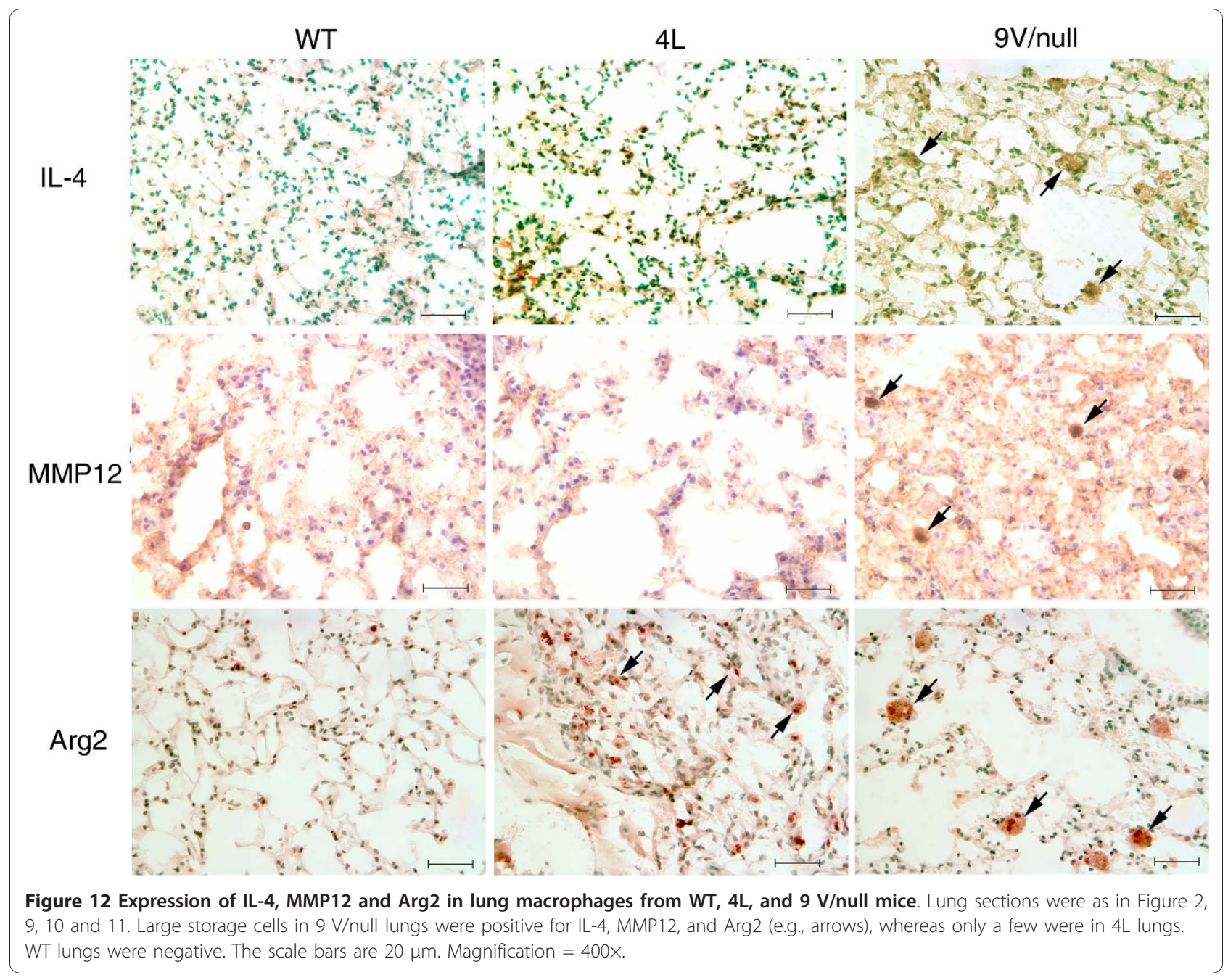

progression from 4 to 28 wk. IFN $\gamma$ central to this cascading network with initial mRNA up-regulation of $\beta$ - and $\alpha$-chemokines, as well as Mrs1 (macrophage scavenger receptor 1 ), TNF $\alpha$, and NOS2. Among these interacting factors is the pleiotropic cytokine IL-6, which is a systemic alarm for tissue damage [43-45]. The $\beta$-chemokines, CCL2, CCL3, CCL6, CCL9, CCL19, and the $\alpha$-chemokines, CXCL1, CXCL12, mediate proinflammatory effects in the various types of cells and also have synergetic effects on their targets $[30,33,46]$. The macrophage scavenger receptor 1 (Msr1) has been implicated in many macrophage-associated physiological and pathological processes through endocytosis [47]. NOS2 and arginase were up-regulated at the RNA and protein levels in the $9 \mathrm{~V} /$ null mice, and as has been observed in ex vivo studies [48]. NOS2 produces nitric oxide from arginine and stimulates pro-inflammation [49-51]. NOS2 production in macrophages up-regulates vascular endothelial growth factor (e.g. VEGF) production and activates angiogenic activity $[52,53]$. In comparison, arginase 2 is a negative angiogenic regulator that inhibits NOS2 activity [54]. Thus, arginase 2 and NOS2 alternative pathways in activated macrophages [24] and their up-regulation in $9 \mathrm{~V} /$ null mice simultaneous pro- and anti-inflammatory networks are being activated in the Gaucher disease process.

Interrogation of the IL-4 mediated anti-inflammatory network highlights significantly differential expression of 11 anti-inflammatory genes, indicating that participation of the aam $\phi$ IL- 4 pathway that counteract expression of macrophage pro-inflammatory cytokines and induce molecules that facilitate tolerance, healing and expression of innate immunity receptors, e.g. the scavenger receptor, CD163 [7,55,56]. The IL-4 pathway (Figure 15B) displays the IL-4 time course and interactions over the 4 to $28 \mathrm{wk}$ period. After an initial lag period from 4 to $12 \mathrm{wk}$, a network of such Th2 response genes $[57,58]$ is up-regulated at the RNA and/or protein levels. This network includes the structurally and functionally related matrix metalloproteinases MMP9/12/19 

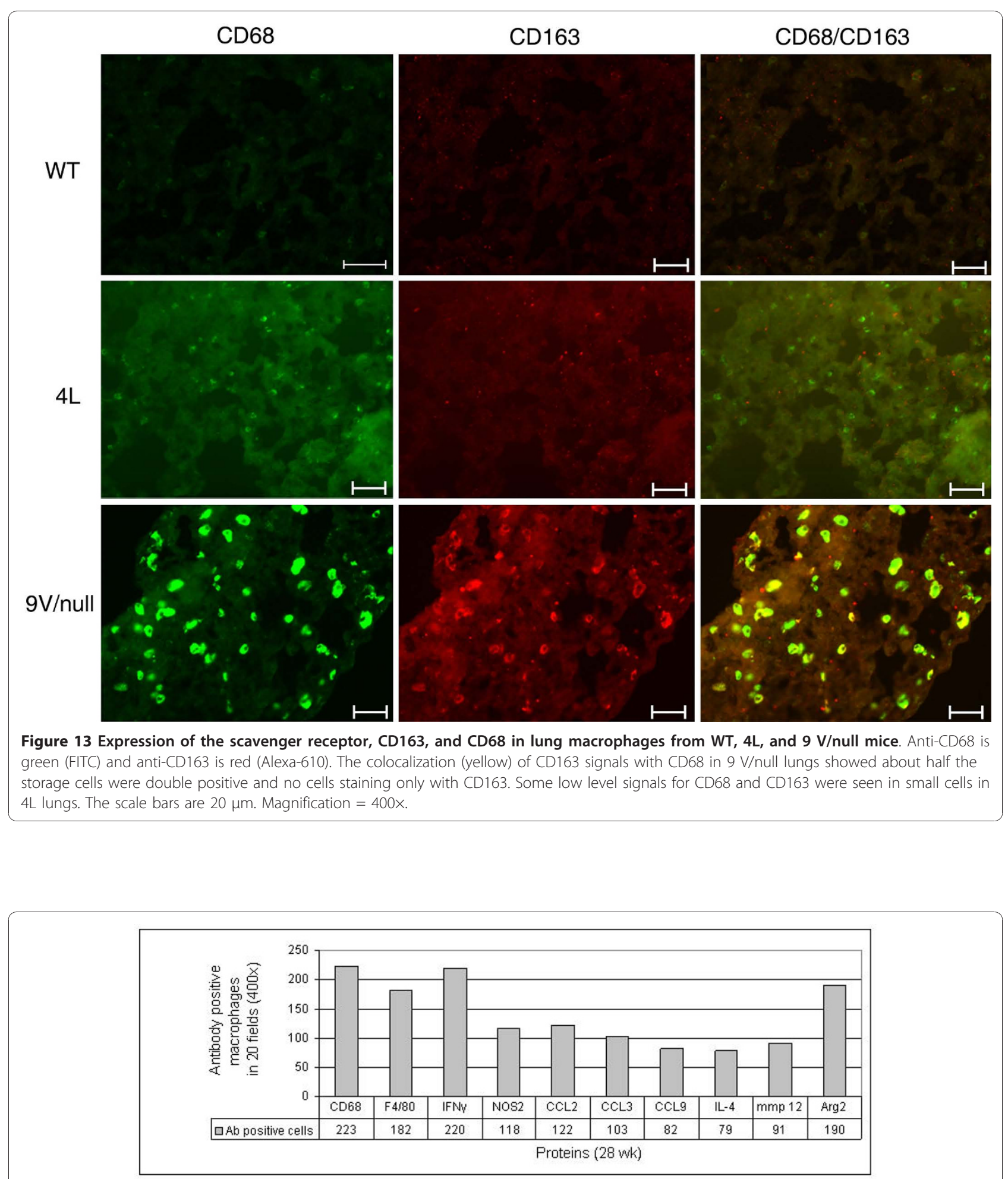

Figure 14 Heterogeneity of cytokine expression in lung macrophages of $\mathbf{9}$ V/null mice. The pro-/anti-inflammatory cytokine antibody stained lung sections from $9 \mathrm{~V}$ /null mice of 28-wk (Figure 9, 10 and 12) were analyzed (20 serial fields at 400x). The antibody positive macrophages were quantified in each field, and plotted (Y-axis) for each cytokine protein (X-axis). The numbers below each column are the respective antibody positive macrophages counts. 


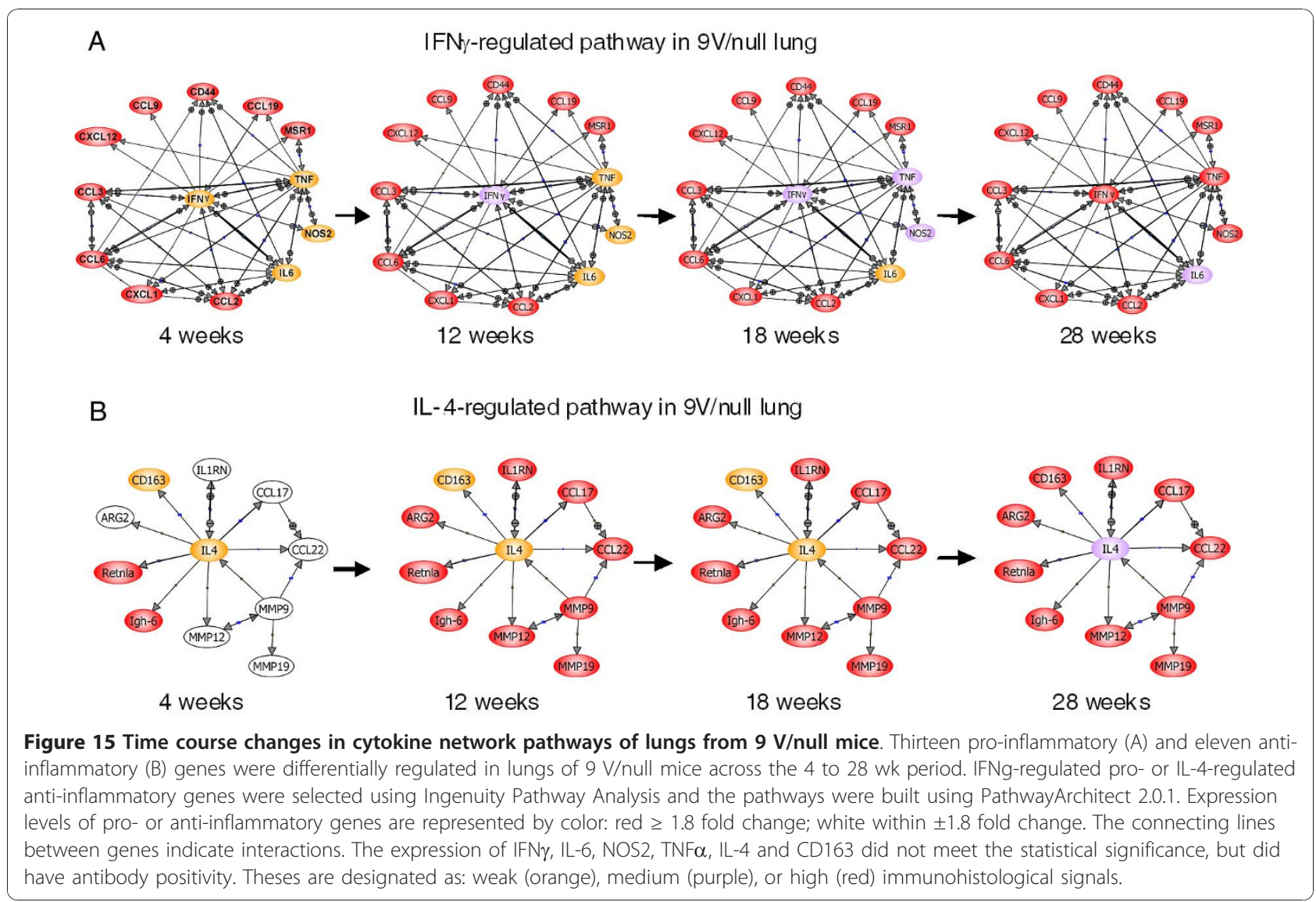

that are endopeptidases important to remodeling processes $[9,17,59,60]$. These MMPs are among the most highly-expressed genes in most $9 \mathrm{~V} /$ null tissues. The high level expression of MMPs correlated with chronic fibrotic processes in $9 \mathrm{~V} /$ null lung and liver (unpublished observation). MMP12 expression occurs in human alveolar macrophages $[18,61]$ and airway smooth muscle cells [62], and in murine alveolar type II epithelial cells [63] or primary lung fibroblasts [64]. The immunohistochemistry showed very strong signals in
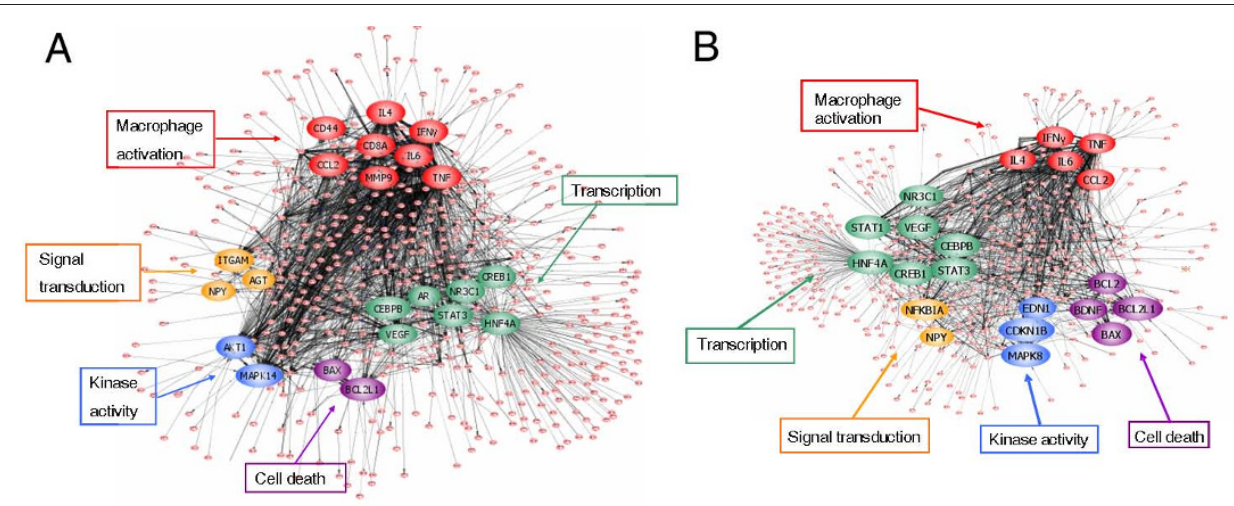

Figure 16 Global gene expression network profiles. In 9 V/null lung 391 genes (A) and in 4L lung 345 genes (B) were analyzed as a cascade network using PathwayArchitect 2.0.1 and Ingenuity Pathways Analysis programs. These genes had a high confidence index of direct and indirect interaction with IFN $\gamma / \mathrm{LL}-4$ macrophage activation genes, which function as core genes (red) and connect to the cascade network via key genes. Gene interactions are shown by the connecting lines. The key genes are those that can be connected to multiple genes. The major key genes are highlighted with different colors for macrophage activation (red), transcription (green), kinase activity (blue), cell death (purple), and signal transduction (yellow) (Additional file 8). 
the lipid-laden macrophages, and much weaker signals in other lung cells (Figure 12). The extremely high level of MMP12 expression (37 to 56-fold in $9 \mathrm{~V} /$ null lung and 16 to 22 -fold in $9 \mathrm{~V} /$ null liver) implicates the aam $\phi$ in Gaucher disease progression.

The aam $\phi$ s are also implicated in the disease progression in $9 \mathrm{~V} /$ null mice as evidenced by CD163 expression $[10,65]$ and, particularly, expression of the IL-1 receptor antagonist (IL-1rn). IL-1rn inhibits the activities of IL-1A and $\mathrm{IL}-1 \mathrm{~B}$, and modulates $\mathrm{IL}-1$ related immune and inflammatory responses. IL-1rn is typically produced by aam $\phi$ and regulated by IL-4 [66,67]. The interactions of these anti-inflammatory cytokines are schematically shown in Figure 15 and indicate an overall description of pro-/anti-inflammatory networks in Gbal mutant mice.

The global gene expression networks integrate the gene expression patterns observed in $9 \mathrm{~V} /$ null or $4 \mathrm{~L}$ mice. In these networks, more than $1 / 3$ of significantly expressed genes were connected through the cascade interactions of pro- and anti-inflammatory genes. Although the macrophage involvement is major histopathological finding, about $3 \%$ of the genome was significantly altered at a molecular level during the development of the disease process. The propagation of the disease clearly depends on a generalized pro- and anti-inflammatory disruption.

Macrophages display marked phenotype heterogeneity in vitro and in vivo, including the responsiveness to endogenous and exogenous stimuli [8]. Such heterogeneity results in differential phagocytosis or endocytosis, intracellular signaling and gene activation or repression $[21,68]$. Macrophage heterogeneity was observed in the $9 \mathrm{~V} /$ null and $4 \mathrm{~L}$ models by their differential activation and tissue distribution. Large lipid-laden macrophages (CD68 and F4/80 positive) were mostly observed in the lung of $9 \mathrm{~V} /$ null mice. Quantitative immunohistochemistry showed only some cytokines/effectors (i.e., IL-6, NOS2, CCL2, CCL3, CCL9, IL-4, and MMP12) were present in $\sim 50 \%$ of lung macrophages (Figure 14). However, IFN $\gamma$ and Arg2 were present in nearly all of such macrophages. The corresponding RNAs of the cytokine/ effectors were also up regulated. The basis for this heterogeneous expression of cytokine proteins in macrophages is unknown, but may be due to the different origins, differentiation sates, or maturation of the macrophage populations.

The genetic background of mice can influence gene expression profiles. Interstrain variations (1-3\%) of gene expression profiles have been shown in different brain regions of mouse inbred strains [69-72]. For example, such variation can be observed in the differential susceptibility to a wide range of pathogens [73-76]. Here, 9 $\mathrm{V} /$ null and 4L mice had mixed strain backgrounds from three in-bred mouse strains FVB and/or C57BL/6J$129 \mathrm{~Sv}$. To evaluate the potential effects of mouse strain background on the expression profiles of macrophage activation genes, the WT data sets from FVB and three inbred mixed strains were used in the analyses. The result showed $>50 \%$ of significantly expressed macrophage activation genes were shared when either of the two background controls were used. There was $83 \%$ concordance in the INF $\gamma$ - and IL-4- regulated pathway genes. In addition, comparative analyses were conducted with duplicate lung RNA chip data from WT adult mice of three different genetic backgrounds (FVB, C57BL/6J, or $129 \mathrm{~Sv})$. The combined WT data generated 790 significantly expressed genes in $9 \mathrm{~V} /$ null lung (data not shown). About $60 \%$ of significantly expressed macrophage genes were concordant between FVB only or strain-matched WT controls, including $>90 \%$ of INF $\gamma$-/ IL4-regulated pathway genes (data not shown). The results showed general agreement of the gene expression profiles from individual WT backgrounds with those from WT controls either pure FVB or strain-matched backgrounds. The results show that macrophage activation genes are a significant functional group in the propagation of Gaucher disease in several genetic backgrounds.

\section{Conclusions}

We demonstrated direct relationships between the degree of tissue glucosylceramides and the gene expression profile alterations. These analyses implicate IFN $\gamma$ regulated pro-inflammatory and IL-4-regulated antiinflammatory networks in differential disease progression with implications for understanding the Gaucher disease course and pathophysiology.

\section{Methods}

\section{Materials}

The following were from commercial sources: RNA Later and TOTALLY RNA kit (Ambion, Austin, TX). Antibody sources are as the follows: Anti-INF $\gamma$, CCL2, CCL3, CCL9, CD68, F4/80, IL-4, CD68, and Goat antirat-HRP (Serotec, Raleigh, NC). Anti-TNF $\alpha$ (Biosource, Camarillo, CA). Anti-Arg1, Arg2 and CD163 (Santa Cruz, CA). Anti-NOS2 (Chemicon, Temecula, CA), Anti-IL6 ( R \& D, Minneapolis, MN). Anti-MMP12 (Biomol, Plymouth Meeting, PA). Horse anti-goatHRP, ABC Vectastain and DAB Substrate Kit (Vector laboratory, Burlingame, CA). Sheep anti-mouse-HRP, Streptavidin-Alexa Fluor 488, Goat anti-rabbit Alexa Flour610, Goat anti-rabbit-HRP (Molecular Probes, Irvine, CA). High Capacity cDNA Archive Kit and SYBR Green PCR Master Mix (Applied Biosystems, Foster City, CA). 


\section{Gba1 mutated mice}

V394L/V394L homozygote (4L) and D409V/null mice (9 $\mathrm{V} /$ null) were generated with mixed genetic backgrounds. $4 \mathrm{~L}$ mice were $50 \%$ of $\mathrm{C} 57 \mathrm{BL} / 6 \mathrm{~J}$ and $129 \mathrm{SvEvBrd}$ and $9 \mathrm{~V} /$ null mice were $50 \%$ of FVB, $25 \%$ of C $57 \mathrm{BL} / 6 \mathrm{~J}$ and129SvEvBrd [16]. The wild-type (WT) controls were strain genetic background matched adult mice (50\% of FVB, 25\% of C57BL/6J and129SvEvBrd,). All mice were housed under pathogen-free conditions in the barrier animal facility and according to IACUC standard procedures at Cincinnati Children's Hospital Research Foundation.

\section{Glycosphingolipid analyses}

Glycosphingolipids in liver and lung from Gba1 mutant and WT mice (5 mg tissues) were extracted with chloroform and methanol as described [77]. Glucosylceramide analysis was carried out by ESI-LC-MS/MS using a Waters Quattro Micro API triple quadrupole mass spectrometer (Milford, MA) interfaced with Acquity UPLC system. The ESI-MS/MS was operated in the multiple reaction monitoring mode for monitoring transition pair of the individual protonated parent ions and their common daughter ion $\mathrm{m} / \mathrm{z} 264$. Calibration curves were built for C16, C18 and C24:1 $\beta$-glucosylceramides using C12 $\beta$-glucosylceramide as an internal standard (Matreya, LLC and Avanti Polar lipids, Inc.). The extracted glycosphingolipid samples were suspended in methanol containing internal standard and injected (10 $\mu \mathrm{L}$ ) into the LC/MS. The level of total glucosylceramide in the liver and lung were normalized to $\mathrm{mg}$ tissue weight.

\section{RNA preparation and microarray hybridization}

Lungs and livers were collected from $9 \mathrm{~V} /$ null and $4 \mathrm{~L}$ mice at the age of 4,12, 18 and $28 \mathrm{wk}$, and from genetic background matched adult WT mice (28 wk) and agematched FVB WT mice (4 - 28 wk) for total RNA preparation. Collected tissues were immediately immersed in RNA Later and tissue RNAs were extracted using the TOTALLY RNA kit. Each tissue RNA set for microarray analysis was pooled from 3 age and genotype matched mice and at least duplicate sample sets for each genotype, tissue, and age were used. This represents 39 labeled RNA sample sets (4 WT, $89 \mathrm{~V} /$ null and $84 \mathrm{~L}$ lung RNAs; 3 WT, $89 \mathrm{~V} /$ null and 8 4L liver RNAs) were submitted to the CCHRF Affymetrix Microarray Core for hybridization to Affymetrix GeneChip Mouse Genome 4302.0 Arrays using standardized protocols. Labeled cRNA synthesis, GeneChip hybridization, washing and staining followed standard Affymetrix protocols. The probed arrays were scanned with the Affymetrix GeneChip ${ }^{\circledR}$ Scanner 3000 and the intensities of array signals were captured with GeneChip Operating Software
(GCOS) v1.1.0, according to standard Affymetrix procedures. The entire microarray data set is available at the Gene Expression Omnibus (GEO) accessible through GEO series accession number GSE23408.

\section{GeneChip quality assessment}

Array data were evaluated for quality assessment using the procedures in the Affymetrix based on scaling factor (10-50), percent present ( $>30 \%)$, and housekeeping gene yielding 3'/5' signal ratios $<3$. Global normalization for outliers or "bad chips" was conducted with each sample/ chip. The normalized intensity values were subjected to hierarchical clustering to determine the relative signal intensity of tissue RNA samples derived from different developmental stages and to identify the outlier(s) or bad chips. GeneChips that passed these screenings were used for subsequent analyses to identify significantly affected genes in tissues of $4 \mathrm{~L}$ and $9 \mathrm{~V} /$ null mice at various time points. To evaluate the affects of strain or genetic background, additional control chip data were from age-matched WT FVB mice ( 4 to $28 \mathrm{wk}, 2$ chips for each age group).

\section{Microarray data normalization and analysis}

The chip data for each mouse variant and corresponding WT controls with 2 tissue types and 4 different time points were loaded into Partek Genomics Suite 6.4 (Partek, Inc., St Louis, MO) and normalized using the RMA (robust multiarray average) algorithm [78]. Sample relationships were examined using principal components analyses that revealed no strong technical effects, which may encumber the subsequent analyses. To identify expression changes between genotypes, a mixed-model ANOVA was performed and chosen to partition subject, tissue, age, and genotype. The following linear mixed model (equation) was generated to detect differential expression on a gene-by-gene basis:

$$
\mathrm{Y}_{\mathrm{ijkm}}=\mathrm{G}_{\mathrm{i}}+\mathrm{T}_{\mathrm{j}}+\mathrm{A}_{\mathrm{k}}+\mathrm{GTA}_{\mathrm{ijk}}+\mathrm{S}_{\mathrm{m}}+\varepsilon_{\mathrm{ijkm}}
$$

Here $Y_{i j k m}$ is the expression of the gene for ith genotype, jth tissue, and kth age, and mth subject. The symbols G, T, A, GTA and S represent effects due to genotype $(\mathrm{G})$, tissue $(\mathrm{T})$, age $(\mathrm{A})$, genotype-by-tissue-byage interaction (GTA), and subject $(S)$. The error for each gene for sample $i j k$ is designated $\varepsilon_{i j k m}$. Genotype, tissue, and age are fixed effects, and subject is a random effect in the mixed model. For each comparison, a linear contrast was set up to obtain the relative fold changes between each mutant and WT control for each tissue at all time points. Four contrasts were added in the computation: $9 \mathrm{~V} /$ null vs. control and $4 \mathrm{~L}$ vs. control in lung and liver. False Discovery Rate (FDR) was used to further guard against false positives because of 
multiple testing [79]. FDR was set at $\leq 0.01$ and fold change was set at \pm 1.8 .

\section{Functional classification}

Significantly affected or differentially expressed genes were subjected to an intensive search to identify biological functions. Functional classifications were performed using the Gene Ontology classification obtained through the DAVID Bioinformatics Database (available at http:// david.abcc.ncifcrf.gov/home.jsp), and public information and/or literature references. The enriched functional categories were determined by Fisher Exact Test using the corresponding murine genome as a reference dataset. The significance was set at $p$-value $<0.05$. The differentially expressed genes were grouped into the following categories (Table 1): catalytic activity, cell death, cytoskeleton, immune response, intracellular signaling cascade, kinase activity, lipid metabolic process, lysosome, macrophage activation, response to stress, transcription and transport.

\section{Clustering of gene expression profiles}

Hierarchical cluster analysis of the significantly expressed genes was performed using GeneSpring GX 7.3 (Agilent Technologies, Inc., Santa Clara, CA), which showed the correlated groups of genes and their expression patterns across all time points.

\section{Network and Pathway analysis}

The significantly differentially expressed genes in the lung of $9 \mathrm{~V} /$ null or $4 \mathrm{~L}$ were loaded into PathwayArchitect 2.0.1 (Stratagene, La Jolla, CA) and built into IFN $\gamma$ or IL-4- regulated pathways and global networks. The pathways and networks were constructed based upon the published literature, Ingenuity Pathways Analysis (Ingenuity Systems, Inc), and PathwayArchitect 2.0.1 (Stratagene, La Jolla, CA).

\section{Common genes selection}

The common differentially expressed genes and consistently expressed macrophage activation genes in the lung or liver between $9 \mathrm{~V} /$ null and $4 \mathrm{~L}$ mice were displayed as Venn diagrams.

\section{Real-time RT-PCR}

To verify selected targets from the RNA chip data, realtime RT-PCR assays were developed. RNAs $(10 \mu \mathrm{g})$ from the same pooled samples as used for microarray chip analyses were used for real-time RT-PCR assays. Each RNA sample was reverse-transcribed (RT) using High Capacity cDNA Archive Kit to synthesize total RNA-cDNA templates with random hexamers. Realtime RT-PCR was conducted using SYBR Green PCR Master Mix with sequence specific primers for CCL9,
Msr1, CCL17, MMP12, and $\beta$-actin cDNA (Additional file 7 Table S2). The reaction mixtures were incubated in $\mathrm{ABI} /$ Prism7000 Sequence Detection System for 40 cycles $\left(95^{\circ} \mathrm{C}, 15 \mathrm{sec}\right.$ and $\left.60^{\circ} \mathrm{C}, 20 \mathrm{sec}\right)$. The primers were designed with Primer Expression 2.0 (Applied Biosystems) and spanned exon/exon conjunctions (Additional file Table S2). The real-time RT-PCR signals from each RNA primer set were normalized by $\beta$-actin signals.

\section{Histological studies}

Mouse tissues (liver and lung) were collected and fixed in $10 \%$ buffered formalin for hematoxylin and eosin (H\&E) staining and light microscopic studies. For immunohistochemistry and immunofluorescence staining, tissues were fixed in $4 \%$ paraformaldehyde/phosphate buffered saline (PBS), $\mathrm{pH} 7.4$, and processed for frozen sections. Tissue sections were blocked with $5 \%$ nonfat milk containing $0.4 \%$ Triton X-100 in PBS. Tissue sections were incubated with primary anti-mouse cytokine antibodies at $4^{\circ} \mathrm{C}$ overnight, and then with the compatible secondary antibodies at room temperature $(1 \mathrm{~h})$. The secondary antibodies were conjugated with fluorescene or horseradish peroxidase (HRP), or a biotinylated secondary antibody/streptavidin-dye system was used. CD68 (FITC) was used as a macrophage marker, and cytokines were detected using specific antibodies and biotin/streptavidin-conjugated dye Alexa Fluor-610. Positively stained macrophages were quantified using a series of 20 frames (magnification 400x) and counted using MetaMorph 6.1 (Universal Imaging Corp, Downingtown, PA).

\section{Additional material}

\begin{tabular}{|c|}
\hline $\begin{array}{l}\text { Additional file 1: Differentially expressed genes in the lungs and } \\
\text { livers of } 9 \text { V/null and } 4 \mathrm{~L} \text { mice. Listed significantly differentially } \\
\text { expressed genes in the lungs and livers of Gaucher mouse models D409 } \\
\text { V/null ( } 9 \mathrm{~V} / \text { null) and V394L (4L). }\end{array}$ \\
\hline $\begin{array}{l}\text { Additional file 2: Classification of differentially expressed genes in } \\
\text { the lungs and livers of } 9 \mathrm{~V} / \text { null and } 4 \mathrm{~L} \text { mice. Listed functional } \\
\text { classification of differentially expressed genes in the lungs and livers of } 9 \\
\mathrm{~V} / \text { null and } 4 \mathrm{~L} \text { mice. }\end{array}$ \\
\hline $\begin{array}{l}\text { Additional file 3: Differentially expressed genes in } 9 \text { V/null lungs } \\
\text { (cluster } 1 \text { in Figure 1). Listed differentially expressed genes and their } \\
\text { functional classification in the lungs of } 9 \mathrm{~V} / \text { null mice (cluster } 1 \text { in Figure 1). }\end{array}$ \\
\hline $\begin{array}{l}\text { Additional file 4: Consistently and significantly expressed } \\
\text { macrophage activation genes in } 9 \mathrm{~V} / \text { null and } 4 \mathrm{~L} \text { tissues. Listed up-/ } \\
\text { down-regulated and consistently expressed macrophage activation } \\
\text { genes in the lungs and livers of } 9 \mathrm{~V} / \text { null and } 4 \mathrm{~L} \text { mice. }\end{array}$ \\
\hline $\begin{array}{l}\text { Additional file 5: Common and unique macrophage activation } \\
\text { genes in } 9 \mathrm{~V} / \text { null and } 4 \mathrm{~L} \text { tissues. Listed common and unique } \\
\text { macrophage activation genes in the lungs or livers between } 9 \mathrm{~V} / \text { null and } \\
4 \mathrm{~L} \text { mice. }\end{array}$ \\
\hline $\begin{array}{l}\text { dditional file 6: Differentially expressed genes in } 9 \text { V/null lung vs. } \\
\text { VT with various backgrounds. Listed differentially expressed global } \\
\text { enes and macrophage activation genes and their commonality in } 9 \mathrm{~V} / \\
\text { ull lungs vs. WT with various backgrounds. }\end{array}$ \\
\hline
\end{tabular}

Additional file 1: Differentially expressed genes in the lungs and expressed genes in the lungs and livers of Gaucher mouse models D409 Additional file 2: Classification of differentially expressed genes in the lungs and livers of $9 \mathrm{~V} /$ null and $4 \mathrm{~L}$ mice. Listed functional classification of differentially expressed genes in the lungs and livers of 9 $\mathrm{V} /$ null and $4 \mathrm{~L}$ mice.

Additional file 3: Differentially expressed genes in $9 \mathrm{~V} /$ null lung (cluster 1 in Figure 1). Listed differentially expressed genes and thei functional classification in the lungs of $9 \mathrm{~V} /$ null mice (cluster 1 in Figure 1). Additional file 4: Consistently and significantly expressed macrophage activation genes in $9 \mathrm{~V} /$ null and $4 \mathrm{~L}$ tissues. Listed up-/ down-regulated and consistently expressed macrophage activation genes in $9 \mathrm{~V} /$ null and $4 \mathrm{~L}$ tissues. Listed common and unique macrophage activation genes in the lungs or livers between $9 \mathrm{~V} /$ null and

null lungs vs. WT with various backgrounds. 
Additional file 7: Table S1. The effect of WT mouse strain background on the gene expression profiles Analysis of altered genes in $9 \mathrm{~V} /$ null lung against the different wild type (WT) backgrounds: FVB/129SV/C57BL6J mix or FVB WT. Table S2. Primers for real-time RT-PCR. Listed the primers for real-time RT-PCR analyses.

Additional file 8: Differentially expressed genes in network in $9 \mathrm{~V} /$ null and $4 \mathrm{~L}$ lungs. Listed differentially expressed genes in network and their functional classification in $9 \mathrm{~V} /$ null and $4 \mathrm{~L}$ lungs.

\section{Acknowledgements}

The authors thank Venette Inskeep for her excellent technical assistance; Lisa McMillin and Meredith Farmer for skilled tissue preparation; Drs. Daniel Prows and Yan Xu for providing their mouse WT lung microarray data. This work was supported by a NIH grant (R01DK 36729) to GAG.

\section{Author details}

'The Division of Human Genetics, Cincinnati Children's Hospital Research Foundation, Cincinnati, OH 45229-3039, USA. ${ }^{2}$ The Division of Pathology and Laboratory Medicine, Cincinnati Children's Hospital Research Foundation, Cincinnati, OH 45229-3039, USA. ${ }^{3}$ The Division of Biomedical Informatics, Cincinnati Children's Hospital Research Foundation, Cincinnati, OH 452293039, USA.

\section{Authors' contributions}

YHX drafted the manuscript, participated in the design the study, and contributed to experiment. $\amalg$ contributed to bioinformatic analyses. $B Q$ and $\mathrm{MZ}$ contributed to experiment. KS contributed to histological analyses. BA contributed to bioinformatic analyses. YS, WJZ and KDRS contributed to glucosylceramide analyses. GAG initiated, guided the study project, and drafted the manuscript. All authors read and approved the final manuscript

\section{Competing interests}

The authors declare that they have no competing interests.

Received: 24 August 2010 Accepted: 11 January 2011 Published: 11 January 2011

\section{References}

1. Beutler E, Grabowski GA: Gaucher Disease. In The Metabolic and Molecular Basis of Inherited Disease. Volume III. eighth edition. Edited by: Scriver CR, Beaudet AL, Sly WS, Valle D. New York: McGraw-Hill; 2001:3635-3668.

2. Barak V, Acker M, Nisman B, Kalickman I, Abrahamov A, Zimran A, Yatziv S: Cytokines in Gaucher's disease. Eur Cytokine Netw 1999, 10(2):205-210.

3. Hollak CE, Evers L, Aerts JM, van Oers MH: Elevated levels of M-CSF, sCD14 and IL8 in type 1 Gaucher disease. Blood Cells Mol Dis 1997, 23(2):201-212.

4. Michelakakis H, Spanou C, Kondyli A, Dimitriou E, Van Weely S, Hollak CE, Van Oers MH, Aerts JM: Plasma tumor necrosis factor-a (TNF-a) levels in Gaucher disease. Biochim Biophys Acta 1996, 1317(3):219-222

5. Boven LA, van Meurs M, Boot RG, Mehta A, Boon L, Aerts JM, Laman JD: Gaucher cells demonstrate a distinct macrophage phenotype and resemble alternatively activated macrophages. Am J Clin Pathol 2004, 122(3):359-369.

6. Frings W, Dreier J, Sorg C: Only the soluble form of the scavenger receptor CD163 acts inhibitory on phorbol ester-activated Tlymphocytes, whereas membrane-bound protein has no effect. FEBS Lett 2002, 526(1-3):93-96.

7. Goerdt S, Politz O, Schledzewski K, Birk R, Gratchev A, Guillot P, Hakiy N, Klemke CD, Dippel E, Kodelja V, et al: Alternative versus classical activation of macrophages. Pathobiology 1999, 67(5-6):222-226.

8. Gordon S: Alternative activation of macrophages. Nat Rev Immunol 2003, 3(1):23-35

9. Gratchev A, Guillot P, Hakiy N, Politz O, Orfanos CE, Schledzewski K, Goerdt S: Alternatively activated macrophages differentially express fibronectin and its splice variants and the extracellular matrix protein betalG-H3. Scand J Immunol 2001, 53(4):386-392

10. Mantovani A, Sozzani S, Locati M, Allavena P, Sica A: Macrophage polarization: tumor-associated macrophages as a paradigm for polarized M2 mononuclear phagocytes. Trends Immunol 2002, 23(11):549-555.
11. Cuvillier O: Sphingosine in apoptosis signaling. Biochim Biophys Acta 2002, 1585(2-3):153-162

12. Obeid LM, Linardic CM, Karolak LA, Hannun YA: Programmed cell death induced by ceramide. Science 1993, 259(5102):1769-1771.

13. Pettus BJ, Chalfant CE, Hannun YA: Sphingolipids in inflammation: roles and implications. Curr Mol Med 2004, 4(4):405-418.

14. Hong YB, Kim EY, Jung SC: Down-regulation of $\mathrm{BCl}-2$ in the fetal brain of the Gaucher disease mouse model: a possible role in the neuronal loss. J Hum Genet 2004, 49(7):349-354.

15. Myerowitz R, Mizukami H, Richardson KL, Finn LS, Tifft CJ, Proia RL: Global gene expression in a type 2 Gaucher disease brain. Mol Genet Metab 2004, 83(4):288-296.

16. Xu YH, Quinn B, Witte D, Grabowski GA: Viable mouse models of acid beta-glucosidase deficiency: the defect in Gaucher disease. Am J Pathol 2003, 163(5):2093-2101.

17. Nenan S, Boichot E, Lagente V, Bertrand CP: Macrophage elastase (MMP12): a pro-inflammatory mediator? Mem Inst Oswaldo Cruz 2005, 100(Suppl 1):167-172.

18. Shapiro SD, Kobayashi DK, Ley TJ: Cloning and characterization of a unique elastolytic metalloproteinase produced by human alveolar macrophages. J Biol Chem 1993, 268(32):23824-23829.

19. Lam-Yuk-Tseung S, Gros P: Genetic control of susceptibility to bacterial infections in mouse models. Cell Microbiol 2003, 5(5):299-313.

20. Pradines JR, Farutin V, Rowley S, Dancik V: Analyzing protein lists with large networks: edge-count probabilities in random graphs with given expected degrees. J Comput Biol 2005, 12(2):113-128.

21. de Fougerolles AR, Chi-Rosso G, Bajardi A, Gotwals P, Green CD, Koteliansky VE: Global expression analysis of extracellular matrix-integrin interactions in monocytes. Immunity 2000, 13(6):749-758.

22. Boehm U, Klamp T, Groot M, Howard JC: Cellular responses to interferongamma. Annu Rev Immunol 1997, 15:749-795.

23. Fenton MJ, Vermeulen MW, Kim S, Burdick M, Strieter RM, Kornfeld H: Induction of gamma interferon production in human alveolar macrophages by Mycobacterium tuberculosis. Infect Immun 1997, 65(12):5149-5156.

24. Munder M, Eichmann K, Moran JM, Centeno F, Soler G, Modolell M: Th1/ Th2-regulated expression of arginase isoforms in murine macrophages and dendritic cells. J Immunol 1999, 163(7):3771-3777.

25. Xing Z, Zganiacz A, Santosuosso M: Role of IL-12 in macrophage activation during intracellular infection: IL-12 and mycobacteria synergistically release TNF-alpha and nitric oxide from macrophages via IFN-gamma induction. J Leukoc Biol 2000, 68(6):897-902.

26. Xaus J, Cardo M, Valledor AF, Soler C, Lloberas J, Celada A: Interferon gamma induces the expression of p21waf-1 and arrests macrophage cell cycle, preventing induction of apoptosis. Immunity 1999, 11(1):103-113.

27. Gudmundsson G, Hunninghake GW: Interferon-gamma is necessary for the expression of hypersensitivity pneumonitis. J Clin Invest 1997, 99(10):2386-2390.

28. Chiu BC, Freeman CM, Stolberg VR, Komuniecki E, Lincoln PM, Kunkel SL, Chensue SW: Cytokine-chemokine networks in experimental mycobacterial and schistosomal pulmonary granuloma formation. Am J Respir Cell Mol Biol 2003, 29(1):106-116.

29. Jiang Y, Beller DI, Frendl G, Graves DT: Monocyte chemoattractant protein1 regulates adhesion molecule expression and cytokine production in human monocytes. J Immunol 1992, 148(8):2423-2428.

30. Baggiolini M, Dewald B, Moser B: Interleukin-8 and related chemotactic cytokines-CXC and CC chemokines. Adv Immunol 1994, 55:97-179.

31. Kopydlowski KM, Salkowski CA, Cody MJ, van Rooijen N, Major J, Hamilton TA, Vogel SN: Regulation of macrophage chemokine expression by lipopolysaccharide in vitro and in vivo. J Immunol 1999, 163(3):1537-1544.

32. Ohmori $Y$, Wyner $L$, Narumi $S$, Armstrong $D$, Stoler M, Hamilton TA: Tumor necrosis factor-alpha induces cell type and tissue-specific expression of chemoattractant cytokines in vivo. Am J Pathol 1993, 142(3):861-870.

33. Oppenheim JJ, Zachariae CO, Mukaida N, Matsushima K: Properties of the novel proinflammatory supergene "intercrine" cytokine family. Annu Rev Immunol 1991, 9:617-648.

34. Schall TJ, Bacon KB: Chemokines, leukocyte trafficking, and inflammation. Curr Opin Immunol 1994, 6(6):865-873.

35. Tessier PA, Naccache PH, Clark-Lewis I, Gladue RP, Neote KS, McColl SR: Chemokine networks in vivo: involvement of $\mathrm{C}-\mathrm{X}-\mathrm{C}$ and $\mathrm{C}-\mathrm{C}$ chemokines 
in neutrophil extravasation in vivo in response to TNF-alpha. J Immunol 1997, 159(7):3595-3602.

36. VanOtteren GM, Standiford TJ, Kunkel SL, Danforth JM, Strieter RM: Alterations of ambient oxygen tension modulate the expression of tumor necrosis factor and macrophage inflammatory protein-1 alpha from murine alveolar macrophages. Am J Respir Cell Mol Biol 1995, 13(4):399-409.

37. Wu AJ, Kurrasch RH, Katz J, Fox PC, Baum BJ, Atkinson JC: Effect of tumor necrosis factor-alpha and interferon-gamma on the growth of a human salivary gland cell line. J Cell Physiol 1994, 161(2):217-226.

38. Dorner BG, Scheffold A, Rolph MS, Huser MB, Kaufmann SH, Radbruch A, Flesch IE, Kroczek RA: MIP-1alpha, MIP-1beta, RANTES, and ATAC/ lymphotactin function together with IFN-gamma as type 1 cytokines. Proc Natl Acad Sci USA 2002, 99(9):6181-6186.

39. Gong JH, Ratkay LG, Waterfield JD, Clark-Lewis I: An antagonist of monocyte chemoattractant protein 1 (MCP-1) inhibits arthritis in the MRL-Ipr mouse model. J Exp Med 1997, 186(1):131-137.

40. Gunn MD, Nelken NA, Liao X, Williams LT: Monocyte chemoattractant protein-1 is sufficient for the chemotaxis of monocytes and lymphocytes in transgenic mice but requires an additional stimulus for inflammatory activation. J Immunol 1997, 158(1):376-383.

41. Rand ML, Warren JS, Mansour MK, Newman W, Ringler DJ: Inhibition of T cell recruitment and cutaneous delayed-type hypersensitivity-induced inflammation with antibodies to monocyte chemoattractant protein-1. Am J Pathol 1996, 148(3):855-864.

42. Zisman DA, Kunkel SL, Strieter RM, Tsai WC, Bucknell K, Wilkowski J, Standiford TJ: MCP-1 protects mice in lethal endotoxemia. J Clin Invest 1997, 99(12):2832-2836.

43. Schindler R, Mancilla J, Endres S, Ghorbani R, Clark SC, Dinarello CA: Correlations and interactions in the production of interleukin-6 (IL-6), IL1 , and tumor necrosis factor (TNF) in human blood mononuclear cells: IL-6 suppresses IL-1 and TNF. Blood 1990, 75(1):40-47.

44. Tilg H, Trehu E, Atkins MB, Dinarello CA, Mier JW: Interleukin-6 (IL-6) as an anti-inflammatory cytokine: induction of circulating IL-1 receptor antagonist and soluble tumor necrosis factor receptor p55. Blood 1994, 83(1):113-118.

45. Xing Z, Gauldie J, Cox G, Baumann H, Jordana M, Lei XF, Achong MK: IL-6 is an antiinflammatory cytokine required for controlling local or systemic acute inflammatory responses. J Clin Invest 1998, 101(2):311-320.

46. Miller MD, Krangel MS: Biology and biochemistry of the chemokines: a family of chemotactic and inflammatory cytokines. Crit Rev Immunol 1992, 12(1-2):17-46.

47. Emi M, Asaoka $H$, Matsumoto A, Itakura $H$, Kurihara $Y$, Wada $Y$, Kanamori $H$, Yazaki $Y$, Takahashi E, Lepert $M$, et al: Structure, organization, and chromosomal mapping of the human macrophage scavenger receptor gene. J Biol Chem 1993, 268(3):2120-2125.

48. Wang WW, Jenkinson CP, Griscavage JM, Kern RM, Arabolos NS, Byrns RE, Cederbaum SD, Ignarro $\amalg$ : Co-induction of arginase and nitric oxide synthase in murine macrophages activated by lipopolysaccharide. Biochem Biophys Res Commun 1995, 210(3):1009-1016.

49. de Vera ME, Shapiro RA, Nussler AK, Mudgett JS, Simmons RL, Morris SM Jr, Billiar TR, Geller DA: Transcriptional regulation of human inducible nitric oxide synthase (NOS2) gene by cytokines: initial analysis of the human NOS2 promoter. Proc Natl Acad Sci USA 1996, 93(3):1054-1059.

50. Mock BA, Krall MM, Byrd LG, Chin H, Barton CH, Charles I, Liew FY, Blackwell J: The inducible form of nitric oxide synthase (NOS2) isolated from murine macrophages maps near the nude mutation on mouse chromosome 11. Eur J Immunogenet 1994, 21(4):231-238.

51. Rossi A, Kapahi P, Natoli G, Takahashi T, Chen Y, Karin M, Santoro MG: Antiinflammatory cyclopentenone prostaglandins are direct inhibitors of IkappaB kinase. Nature 2000, 403(6765):103-108.

52. Leibovich SJ, Polverini PJ, Fong TW, Harlow LA, Koch AE: Production of angiogenic activity by human monocytes requires an L-arginine/nitric oxide-synthase-dependent effector mechanism. Proc Natl Acad Sci USA 1994, 91(10):4190-4194.

53. Xiong M, Elson G, Legarda D, Leibovich SJ: Production of vascular endothelial growth factor by murine macrophages: regulation by hypoxia, lactate, and the inducible nitric oxide synthase pathway. Am J Pathol 1998, 153(2):587-598.

54. Corraliza IM, Soler G, Eichmann K, Modolell M: Arginase induction by suppressors of nitric oxide synthesis (IL-4, IL-10 and PGE2) in murine bone-marrow-derived macrophages. Biochem Biophys Res Commun 1995, 206(2):667-673.

55. Hogger P, Dreier J, Droste A, Buck F, Sorg C: Identification of the integral membrane protein RM3/1 on human monocytes as a glucocorticoidinducible member of the scavenger receptor cysteine-rich family (CD163). J Immunol 1998, 161(4):1883-1890.

56. Stein M, Keshav S, Harris N, Gordon S: Interleukin 4 potently enhances murine macrophage mannose receptor activity: a marker of alternative immunologic macrophage activation. J Exp Med 1992, 176(1):287-292.

57. Bonecchi R, Sozzani S, Stine JT, Luini W, D'Amico G, Allavena P, Chantry D, Mantovani A: Divergent effects of interleukin-4 and interferon-gamma on macrophage-derived chemokine production: an amplification circuit of polarized T helper 2 responses. Blood 1998, 92(8):2668-2671.

58. Imai T, Nagira M, Takagi S, Kakizaki M, Nishimura M, Wang J, Gray PW, Matsushima K, Yoshie O: Selective recruitment of CCR4-bearing Th2 cells toward antigen-presenting cells by the CC chemokines thymus and activation-regulated chemokine and macrophage-derived chemokine. Int Immunol 1999, 11(1):81-88.

59. Lang R, Kocourek A, Braun M, Tschesche H, Huber R, Bode W, Maskos K: Substrate specificity determinants of human macrophage elastase (MMP-12) based on the 1.1 A crystal structure. J Mol Biol 2001, 312(4):731-742.

60. Liu WH, Chen XM, Fu B: Thrombin stimulates MMP-9 mRNA expression through AP-1 pathway in human mesangial cells. Acta Pharmacol Sin 2000, 21(7):641-645.

61. Belaaouaj A, Shipley JM, Kobayashi DK, Zimonjic DB, Popescu N, Silverman GA, Shapiro SD: Human macrophage metalloelastase. Genomic organization, chromosomal location, gene linkage, and tissue-specific expression. J Biol Chem 1995, 270(24):14568-14575.

62. Xie S, Issa R, Sukkar MB, Oltmanns U, Bhavsar PK, Papi A, Caramori G, Adcock I, Chung KF: Induction and regulation of matrix metalloproteinase-12 in human airway smooth muscle cells. Respir Res 2005, 6:148.

63. Qu P, Du H, Wang X, Yan C: Matrix metalloproteinase 12 overexpression in lung epithelial cells plays a key role in emphysema to lung bronchioalveolar adenocarcinoma transition. Cancer Res 2009, 69(18):7252-7261.

64. Shukla A, Barrett TF, Nakayama KI, Nakayama K, Mossman BT, Lounsbury KM: Transcriptional up-regulation of MMP12 and MMP13 by asbestos occurs via a PKCdelta-dependent pathway in murine lung. Faseb J 2006, 20(7):997-999.

65. Kristiansen M, Graversen JH, Jacobsen C, Sonne O, Hoffman HJ, Law SK, Moestrup SK: Identification of the haemoglobin scavenger receptor. Nature 2001, 409(6817):198-201.

66. Gabay C, Porter B, Guenette D, Billir B, Arend WP: Interleukin-4 (IL-4) and $\mathrm{IL}-13$ enhance the effect of IL-1beta on production of IL-1 receptor antagonist by human primary hepatocytes and hepatoma HepG2 cells: differential effect on C-reactive protein production. Blood 1999, 93(4):1299-1307.

67. Mantovani A, Locati M, Vecchi A, Sozzani S, Allavena P: Decoy receptors: a strategy to regulate inflammatory cytokines and chemokines. Trends Immunol 2001, 22(6):328-336.

68. Peiser L, Mukhopadhyay S, Gordon S: Scavenger receptors in innate immunity. Curr Opin Immunol 2002, 14(1):123-128.

69. Fernandes C, Paya-Cano JL, Sluyter F, D'Souza U, Plomin R, Schalkwyk LC: Hippocampal gene expression profiling across eight mouse inbred strains: towards understanding the molecular basis for behaviour. Eur J Neurosci 2004, 19(9):2576-2582.

70. Korostynski M, Kaminska-Chowaniec D, Piechota M, Przewlocki R: Gene expression profiling in the striatum of inbred mouse strains with distinct opioid-related phenotypes. BMC Genomics 2006, 7:146.

71. Pavlidis P, Noble WS: Analysis of strain and regional variation in gene expression in mouse brain. Genome Biol 2001, 2(10):RESEARCH0042.

72. Sandberg R, Yasuda R, Pankratz DG, Carter TA, Del Rio JA, Wodicka L, Mayford M, Lockhart DJ, Barlow C: Regional and strain-specific gene expression mapping in the adult mouse brain. Proc Natl Acad Sci USA 2000, 97(20):11038-11043.

73. Bianchi-Frias D, Pritchard C, Mecham BH, Coleman IM, Nelson PS: Genetic background influences murine prostate gene expression: implications for cancer phenotypes. Genome Biol 2007, 8(6):R117. 
74. Burne MJ, Haq M, Matsuse H, Mohapatra S, Rabb H: Genetic susceptibility to renal ischemia reperfusion injury revealed in a murine model. Transplantation 2000, 69(5):1023-1025.

75. Rosas LE, Keiser T, Barbi J, Satoskar AA, Septer A, Kaczmarek J, LezamaDavila CM, Satoskar AR: Genetic background influences immune responses and disease outcome of cutaneous $L$. mexicana infection in mice. Int Immunol 2005, 17(10):1347-1357.

76. Scott MJ, Hoth JJ, Gardner SA, Peyton JC, Cheadle WG: Genetic background influences natural killer cell activation during bacterial peritonitis in mice, and is interleukin 12 and interleukin 18 independent. Cytokine 2004, 28(3):124-136.

77. Sun Y, Quinn B, Witte DP, Grabowski GA: Gaucher disease mouse models: point mutations at the acid beta-glucosidase locus combined with lowlevel prosaposin expression lead to disease variants. J Lipid Res 2005, 46(10):2102-2113.

78. Irizarry RA, Bolstad BM, Collin F, Cope LM, Hobbs B, Speed TP: Summaries of Affymetrix GeneChip probe level data. Nucleic Acids Res 2003, 31(4): e15.

79. Benjamini Y, Drai D, Elmer G, Kafkafi N, Golani I: Controlling the false discovery rate in behavior genetics research. Behav Brain Res 2001, 125(1-2):279-284.

doi:10.1186/1471-2164-12-20

Cite this article as: Xu et al:: Global gene expression profile progression in Gaucher disease mouse models. BMC Genomics 2011 12:20.

\section{Submit your next manuscript to BioMed Central} and take full advantage of:

- Convenient online submission

- Thorough peer review

- No space constraints or color figure charges

- Immediate publication on acceptance

- Inclusion in PubMed, CAS, Scopus and Google Scholar

- Research which is freely available for redistribution

Submit your manuscript at www.biomedcentral.com/submit 